\title{
Analysis of Internal and External Thermal Resistances of Heat Pipes Including Fins Using a Three-Dimensional Numerical Simulation
}

\author{
Leonard M. Poplaski ${ }^{a, *}$, Amir Faghri ${ }^{a}$, Theodore L. Bergman ${ }^{\mathrm{b}}$ \\ ${ }^{a}$ Department of Mechanical Engineering, University of Connecticut, 191 Auditorium Road, Storrs, CT 06269-3139, USA \\ ${ }^{\mathrm{b}}$ Department of Mechanical Engineering, The University of Kansas, 1530 W. 15th St, Lawrence, KS 66045, USA \\ * Corresponding author. Tel.: +1 8604862205 \\ E-mail address: Lenny.poplaski@uconn.edu (L. Poplaski)
}




\begin{tabular}{|c|c|c|c|}
\hline \multicolumn{4}{|c|}{ Nomenclature } \\
\hline A & area $\left(\mathrm{m}^{2}\right)$ & \multicolumn{2}{|l|}{ Subscripts } \\
\hline$c_{p}$ & specific heat $(\mathrm{J} / \mathrm{kgK})$ & $a$ & adiabatic \\
\hline $\boldsymbol{h}$ & heat transfer coefficient $\left(\mathrm{W} / \mathrm{m}^{2} \mathrm{~K}\right)$ & $a b s$ & absolute \\
\hline $\mathrm{h}$ & enthalpy $(\mathrm{J} / \mathrm{kg})$ & act & actual \\
\hline HTHP & high temperature heat pipe & $c$ & condenser \\
\hline $\mathrm{h}_{f g}$ & latent heat $(\mathrm{J} / \mathrm{kg})$ & cell & cell value \\
\hline$k$ & thermal conductivity $(\mathrm{W} / \mathrm{m} \mathrm{K})$ & $\mathrm{D}$ & diameter $(m)$ \\
\hline$L$ & length $(\mathrm{m})$ & $e$ & evaporator \\
\hline LTHP & low temperature heat pipe & eff & effective \\
\hline$\dot{\mathrm{m} "}$ & mass flux $(\mathrm{kg} / \mathrm{s})$ & ex & external \\
\hline$N u$ & Nusselt number & $e x-f$ & external to fin \\
\hline$n$ & normal vector & $e x-w$ & external to wall \\
\hline $\operatorname{Pr}$ & Prandtl number & $\mathrm{f}$ & fluid \\
\hline$p$ & pressure $(\mathrm{Pa})$ & $f$ & fin \\
\hline$Q$ & heat rate $(\mathrm{W})$ & gage & gage value \\
\hline$q "$ & heat flux $\left(\mathrm{J} / \mathrm{m}^{2}\right)$ & $h p$ & heat pipe \\
\hline$R$ & thermal resistance $(\mathrm{W} / \mathrm{K})$ & $i$ & $\mathrm{i}^{\text {th }}$ component, inner \\
\hline$R_{g}$ & universal gas constant $(\mathrm{J} / \mathrm{kg} \mathrm{K})$ & in & input \\
\hline $\mathrm{Re}$ & Reynolds number & inter & interface \\
\hline$r$ & radius $(m)$ & inlet & inlet \\
\hline$T$ & temperature $(\mathrm{K})$ & $l$ & liquid \\
\hline$t$ & thickness (m), time (s) & 0 & outer \\
\hline$V$ & velocity $(\mathrm{m} / \mathrm{s})$ & $o p$ & operating \\
\hline$v$ & specific volume & out & outlet \\
\hline$W$ & work $(\mathrm{J})$, width (m) & $s$ & solid \\
\hline \multirow[t]{2}{*}{$x, y, z$} & spatial coordinates & sat & saturation \\
\hline & & surr & surrounding \\
\hline \multicolumn{2}{|c|}{ Greek symbols } & tot & total \\
\hline$\varepsilon$ & emissivity & theo & theoretical \\
\hline$\theta$ & circumferential angle & $v$ & vapor \\
\hline$\mu$ & dynamic viscosity $\left(\mathrm{N} \cdot \mathrm{s} / \mathrm{m}^{2}\right)$ & $w$ & wall \\
\hline$\rho$ & density $\left(\mathrm{kg} / \mathrm{m}^{3}\right)$ & $w k$ & wick \\
\hline$\sigma$ & Stefan-Boltzmann constant & 0 & reference value \\
\hline$\tau$ & viscous stress tensor $\left(\mathrm{N} / \mathrm{m}^{2}\right)$ & $\infty$ & free stream \\
\hline$\varphi$ & porosity & & \\
\hline
\end{tabular}




\section{Introduction}

Heat pipe applications range from the cooling of consumer electronics such as laptops [1-2] to thermal management of spacecraft [3]; proposed uses include turbine blade and high speed aircraft wing cooling [2]. A heat pipe generally consists of an evaporator (heat input), a condenser (heat output), and an adiabatic (heat transport) region. Heat pipes are able to achieve high heat transfer rates compared to traditional heat transfer devices due to phase change of the internal working fluid. At the evaporator section, heat is conducted through the heat pipe wall and wick, vaporizing the working fluid in the saturated wick. The vapor flows to the condenser due to a pressure gradient, where it is then condensed and returned to the evaporator by capillary action in the wick.

Two-dimensional simplified numerical models have shown good agreement with experimental results [4-6]. A two-dimensional transient numerical model for a heat pipe with compressible vapor flow was presented by Cao and Faghri [4] to simulate high temperature heat pipe operation. The heat transfer in the wick was assumed to be governed by pure conduction. The numerical model was validated with experimentally obtained pressure and vapor temperature distributions with good success. Buchko and Faghri [6] extended the work of Cao and Faghri [4] by modeling low temperature heat pipes with multiple heat sources and accounted for the effects of porosity and permeability in the wick structure. The effect of spatial distribution of the heat load was investigated, and decomposition of the heat input into multiple locations was found to increase the maximum heat transferred across a single heat pipe. Rice and Faghri [5] performed a detailed numerical analysis of both low and high temperature heat pipes, accounting for flow in the wick to determine the capillary pressure required for the return of the working fluid. Ranjan et al. [7] developed a model including the effects of the wick micro-structure on the overall heat transfer rate. Two numerical models were employed, the first was a macro-model where the phase-change rates and the temperature/pressure at the solid-liquid interface was obtained through an energy balance at the interface. The second method examined the wick micro-structure and computed the phase change rates from the liquid meniscus formed in the pores. The two models were then coupled to predict the performance of a heat pipe with a screen wick.

Zuo and Faghri [8] developed an equivalent thermal network to simplify the simulation of transient heat pipe operation. The thermal resistance of the internal working fluid flow was assumed to be negligible during transient operation, and was therefore excluded in the model. A thermodynamic representation of heat pipe operation was also discussed using a $T-S$ diagram, from which proper heat pipe functionality was justified.

Xiao and Faghri [9] developed a complex numerical model of a three-dimensional flat plate heat pipe, and predicted its thermodynamic behavior without use of empirical correlations. The flow in the vapor core was assumed laminar and incompressible with state properties following the ideal gas relation. The wick was assumed to be saturated with working fluid and have constant transport properties. Inclusion of a vertical column wick was found to lower the 
thermal resistance and increase the capillary limit, resulting in a higher axial pressure drop and larger liquid and vapor velocities. Kaya and Goldak [10] also studied three-dimensional heat pipe operation using the finite element numerical method where the mass, momentum and energy conservation equations were solved for the vapor and liquid flow. The obtained numerical velocity and pressure distributions were verified with experimentally obtained data. It was shown that the vapor flow field remains nearly symmetric around the heat pipe.

Transport of heat by a flat heat pipe with multiple discrete heat sources was evaluated by Vaddakan et al. [11]. The numerical model was used to simulate heat transfer and fluid flow in the wick. The heat input and evaporator locations were varied to determine where and when dry out would first occur. Similar to Buchko and Faghri [6], it was found that a decrease in heat pipe operating temperature can be achieved by separating the heat input into smaller sources with larger separation between each source.

In this work, a numerical model for a three-dimensional cylindrical heat pipe has been developed to analyze the component thermal resistances of the heat pipe, including the external thermal resistances of the heat sources and sinks. A single-domain conjugate approach, with no empirical correlations, was used in order to obtain accurate thermal resistance values. In addition, simulations were performed including the full coolant flow field around the heat pipe condenser. To our knowledge, this is the first attempt to simulate a three-dimensional heat pipe in conjunction with the external flow of coolant. 


\section{Physical model}

\subsection{Background}

Heat pipes are passive two-phase devices capable of high heat transfer rates while maintaining a low temperature drops. Heat input at the evaporator causes the working fluid to vaporize, which flows to the condenser where the hot vapor releases its latent energy to the cooler condenser wick and wall. Capillary action in the wick aids in the return of the working fluid to the evaporator (heat pipes), while wickless heat pipes (thermosyphons) rely on gravity to return the working fluid and are limited to certain inclination angles with the evaporator placed below the condenser. Figure 1 shows the typical elements and configuration of a heat pipe with fins, and a flow channel external to the condenser. The heat pipe consists of three main radial regions: (1) the vapor core, where the evaporated working fluid is transported, (2) the wick, which aids in the return of the condensed working fluid to the evaporator, and (3) the wall which provides structural rigidity. Heat $\left(Q_{i n}\right)$ enters the evaporator $\left(L_{e}\right)$, and leaves at the condenser $\left(L_{c}\right)$. In some numerical cases, fins were included on the condenser outer surface of the heat pipe to aid in the rejection of heat to the external working fluid, of the coolant channel.

\subsection{Governing equations}

The three-dimensional governing equations were solved assuming the vapor flow to be laminar and compressible with constant properties [12].

Conservation of mass:

$$
\frac{\partial \rho}{\partial t}+\nabla \cdot \rho V=0
$$

Conservation of momentum:

$$
\frac{\partial}{\partial t}(\rho V)+\nabla \cdot(\rho V V)=-\nabla p+\nabla \cdot \tau
$$

Conservation of energy:

$$
\frac{D}{D t}(\rho h)+\nabla \cdot q^{\prime \prime}=\frac{D p}{D t}+\nabla V: \tau
$$

where $\nabla V: \tau$ is the viscous dissipation term.

The density of the vapor is described by the ideal gas relation:

$$
\rho=\frac{p}{R T}
$$


The flow in the wick was considered negligible, and the associated convective heat transfer was neglected; thus, the heat transfer in the wick was modeled as pure conduction. Therefore, the governing equations for heat transfer in the wick and wall are given by following form of the heat equation:

$$
\nabla \cdot k \nabla T=\rho c_{p} \frac{\partial T}{\partial t}
$$

The wick is composed of a screen wire mesh with an effective thermal conductivity [13]:

$$
k_{e f f}=\frac{k_{l}\left[k_{l}+k_{s}-(1-\varphi)\left(k_{l}-k_{s}\right)\right]}{\left(k_{l}+k_{S}\right)+(1-\varphi)\left(k_{l}-k_{s}\right)}
$$

where $k_{s}$ and $k_{l}$ are the solid and liquid thermal conductivities, respectively, and $\varphi$ is the porosity of the wick.

The equations for continuity, momentum and energy are solved for the external cooling flow when a heat transfer fluid (HTF) is employed at the condenser surface. It is assumed that the external flow of coolant is steady, laminar and incompressible with negligible buoyancy forces. The walls of the coolant channel are insulated and conductive heat transfer in the channel walls is neglected. The conjugate heat transfer between the heat pipe and coolant was fully simulated, and the contact resistances in the heat pipe and flow channel are assumed to be insignificant.

\subsection{Boundary conditions}

The following boundary conditions are applicable to the cases without external fins. When fins are included on the condenser surface, conduction through the fins is solved and the external fin surface is modeled as a convective boundary similar to the condenser wall.

\section{At the evaporator wall}

In each case with a constant heat flux applied to the evaporator (Cases 1-4, Cases 5: A-C, F and $\mathrm{G})$ :

$$
k \nabla T \cdot n=\left.\frac{Q_{\text {in }}}{A}\right|_{r=r_{0}, 0<\mathrm{y}<\mathrm{L}_{e}}
$$

When a constant heat transfer coefficient convection is applied to the evaporator wall (Cases 5: D, E, H and I), flux matching was performed between Fourier's law and Newton's law of cooling, yielding:

$$
k \nabla T \cdot n=\left.\boldsymbol{h}\left(T_{\infty}-T_{e, e x-w}\right)\right|_{r=r_{0}, 0<\mathrm{y}<\mathrm{L}_{e}}
$$

It should be noted that a value of $\boldsymbol{h}$ is used assuming liquid water as the heat input fluid. 
The heat transfer modes external to the condenser were one of the following: constant heat transfer coefficient convection, constant heat sink, radiative and channel flow. Constant heat transfer coefficient convective heat transfer at the condenser, Equation (8), is applied using the free stream temperature, wall temperature and heat transfer coefficient corresponding to the coolant. In the case of a constant convective boundary condition the value of $\boldsymbol{h}$ is assumed based on previous work's [4-6], and directly applied in Equation (8) (Cases 1-3). When the heat pipe is modeled with channel flow cooling (Case 4 A-D, Case 5: A, E-F), predictions for $\boldsymbol{h}$ are calculated and used to theoretically predict the external condenser thermal resistance.

For radiation:

$$
k \nabla T \cdot n=\varepsilon \sigma\left(T_{\text {surr }}^{4}-T_{c, e x-w}^{4}\right)_{r=r_{0}, \mathrm{~L}_{e}+\mathrm{L}_{\mathrm{a}}<\mathrm{y}<\mathrm{L}_{e}+\mathrm{L}_{\mathrm{a}}+\mathrm{L}_{\mathrm{c}}}
$$

For a constant heat flux heat sink:

$$
k \nabla T \cdot n=\left.\frac{-Q_{i n}}{A}\right|_{r=r_{0}, \mathrm{~L}_{e}+\mathrm{L}_{\mathrm{a}}<\mathrm{y}<\mathrm{L}_{e}+\mathrm{L}_{\mathrm{a}}+\mathrm{L}_{c}}
$$

The channel is described with boundary conditions of: a velocity inlet, pressure outlet and no slip insulated walls.

$$
\text { In the coolant channel }\left(L_{e}+L_{a} \leq y \leq \mathrm{L}_{e}+L_{a}+L_{c}, 0<x<W, z=z_{i n}\right)
$$

an inlet velocity, $V_{\text {inlet }}$, and temperature, $T_{\text {inlet }}$, are specified

$$
\text { At the outlet of the channel }\left(L_{e}+L_{a} \leq y \leq L_{e}+L_{a}+L_{c}, 0<x<W, z=z_{\text {out }}\right)
$$

the gage pressure is set such that:

$$
p_{\text {gage }}=p_{\text {abs }}-p_{\text {op }}=0
$$

At any of the channel wall locations, the heat transfer and velocity are zero. The internal boundary conditions at the wick-vapor interface of the heat pipe are provided by a velocity inlet and temperature boundary.

The energy balance at the wick-vapor interface is used to determine the interfacial velocity for the vapor region:

$$
\dot{q}^{\prime \prime}{ }_{\text {inter }}=\left(\dot{m} h_{f g}\right)_{\text {inter }}=\left(\rho_{v} v_{v} h_{f g}\right)_{\text {inter }}
$$

The Clausius-Clapeyron equation is used to determine the interfacial temperature: 


$$
T_{\text {sat }}=\left[\frac{1}{T_{0}}-\frac{R_{g}}{h_{f g}} \ln \left(\frac{p_{v}}{p_{0}}\right)\right]^{-1}
$$

\section{Thermal resistance network}

Thermal resistance is defined as the ratio of the driving potential (temperature) to the corresponding heat transfer, and is used to identify which component $i$ of the heat pipe restrict heat transfer:

$$
R_{i}=\frac{\Delta T_{i}}{Q_{i}}
$$

where $T_{i}$ is the spatially averaged temperature of the heat pipe component.

The thermal resistance network for a heat pipe is outlined pictorially in Figure 2, and the corresponding equations for each heat pipe component are given in Table 1. For cases involving external channel flow (Case 4 and Case 5 A, F, G, H and I), the heat transfer coefficient $\boldsymbol{h}$ was predicted analytically using [14]:

$$
\overline{\mathrm{Nu}}=0.3+\frac{0.62 \operatorname{Re}_{D}{ }^{1 / 2} \operatorname{Pr}^{1 / 3}}{\left[1+(0.4 / \mathrm{Pr})^{2 / 3}\right]^{1 / 4}}\left[1+\left(\frac{\operatorname{Re}_{D}}{282000}\right)^{5 / 8}\right]^{4 / 5}
$$

The external flow around the heat pipe is the primary area of interest since it has the greatest influence on the heat transfer from the condenser surface; thus the external Reynolds number was calculated based on heat pipe diameter, and found to be laminar in all cases.

\section{Computational methodology}

The governing equations with the associated boundary conditions were solved using the finite-volume approach [15]. Symmetry was assumed about the $y z$ plane of the flow channel; therefore only half of the physical domain was solved. A user defined function (UDF) was written for the commercial software package ANSYS Fluent to set the temperature of the wick-vapor interface and the blowing/suction velocity of the vapor at the interface. The assigned interface velocity emulates the phase change that occurs at the wick surface.

Two solution methods were considered: 1) steady-state and 2) transient. Provided with enough time steps, the transient method converges to the same steady-state solution. Simulations were performed on a Dell Optiplex 7020 (running Microsoft Windows 7 equipped with an Intel i - 4790 processor and 16 GB of RAM). 


\subsection{Steady-state simulations}

For simulations where the time dependent details of operation were of negligible importance, the transient terms in the governing equations were disregarded, and no initial conditions were provided. A pressure gradient appears in governing Equations (2-3), however, no pressure is known in the heat pipe, and therefore an infinite number of steadystate solutions exist for the pressure distribution. The coupling between pressure and saturation temperature (Equation 16) produces an infinite number of steady-state temperature distributions that satisfy the applied boundary conditions. To obtain the unique solution, with the correct heat pipe operating pressure, an iterative process is performed where the vapor end cap closest to the condenser ( $x=0, y=L_{e}+L_{a}+L_{c}$ in Figure 1) is modeled as a pressure outlet and the vapor core is simulated as an open system. With the vapor core modeled as an open system, the pressure difference between the end cap and the vapor allow mass to exit the heat pipe. The mass flow rate through the end cap is then used to calculate the amount of heat leaving the end cap:

$$
Q_{o u t}=\frac{\dot{m}_{o u t}}{h_{f g}}
$$

To reduce the mass leaving the control volume the operating temperature is correct and the corresponding saturation pressure is set as the operating pressure. When the outflow mass is zero, the internal pressure drop is the same as for a closed heat pipe. In this work, the steadystate method was only applied to heat pipes with convective boundary conditions. More information may be found in [5] for steady-state simulations using other boundary condition types. The correction for convective sinks is:

$$
\Delta T=\frac{\dot{m}_{o u t} h_{f g}}{A_{c, o} h}
$$

To properly apply the method outlined above, the following steps must be taken:

1. Supply a guess operating temperature and corresponding pressure

2. Perform steady-state iterations of the governing equations until the mass flow rate has converged

3. Use the mass flow rate to calculate the operating temperature correction $\Delta T$

4. Correct the operating temperature and pressure of the domain

Steps 2-4 are repeated until the net heat rate between the condenser and the evaporator is within a set tolerance. 


\subsection{Transient simulations}

The full set of governing equations are solved including the transient terms using an implicit scheme. The implicit scheme does not have a maximum time step required to prevent divergence, however, more computational time is required than for the steady state formulation.

\subsection{Channel flow convergence}

To reduce computation time, a converged flow field was obtained with and without fins, and then supplied as a guess to the coupled heat pipe channel flow problem. The effects of start-up were not evaluated in the case of channel flow, thus only the previously outlined steady-state solution formulation was utilized.

\section{Results and discussion}

\subsection{High temperature heat pipe (HTHP) verification}

High temperature heat pipes have operating temperatures of $750 \mathrm{~K}$ or above [13], with common working fluids being sodium, silver and lithium. The numerical model was compared with the high temperature experimental and numerical data of sodium filled heat pipes [4-6], to verify its accuracy. The first case (Case 1) tested the consistency of results generated by the steady-state and transient methods for a heat pipe with constant heat input to the evaporator and a condenser cooled by convection. The results were compared to those of Rice and Faghri [5], Cao and Faghri [4] and the experimental data of Ivanovski et al. [16]. Case 2 involves the transient response of the heat pipe to a step heat input. Case 2 simulations were performed for both radiative and convective cooling of the condenser. Results for both cooling conditions were verified with the numerical results of Cao and Faghri [4]. The dimensions of the heat pipes for Case 1 and Case 2 are listed in Table 2, along with their respective working fluids, heat inputs, as well as wall and wick thermophysical properties.

\section{Case 1: HTHP steady state operation}

Overview of Case 1:

- Constant heat rate input $(560 \mathrm{~W})$

- Convective cooling $\left(58.5 \mathrm{~W} / \mathrm{m}^{2} \mathrm{~K}\right)$

- Validated to experimental data of Ivanovski et al. [16]

- Verified to the numerical simulations of Cao and Faghri [4] and Rice and Faghri [5]

Case 1 uses dimensions and properties similar to those of Cao and Faghri [4] and Rice and Faghri [5] to simulate the heat pipe experiments of Ivanovski et al. [16]. The sodium heat pipe has an evaporator heat rate of $560 \mathrm{~W}$, and a condenser cooled by convection with a heat transfer coefficient of $58.5 \mathrm{~W} / \mathrm{m}^{2} \mathrm{~K}$ and reference temperature of $300 \mathrm{~K}$. The simulation proceeded until a steady-state solution was obtained, and was validated with the experimental wall temperature distribution reported by Ivanovski et al. [16]. A similarity solution published by Faghri [17] was used to verify the internal pressure distribution. The computational mesh for Case 1 contained 
40 cells in the axial direction, 10 cells in the radial, and 20 cells in the azimuthal direction. The wick and wall each contained 2 cells while the vapor region contained 6 . The average surface temperatures of the condenser and evaporator were monitored, and less than 0.5 percent variation in each was observed after 2000 iterations. The computation time was approximately 8 hours. The difference between the predicted and measured temperature is largest in the adiabatic region of the heat pipe.

The axial temperature variation are plotted in Figure 3a, and the obtained numerical results are compared to the existing numerical and experimental data, with good agreement. Slight deviations are attributed to the difference in vapor properties used in each study.

In Figure 3b, it can be seen that the numerically obtained pressure drop differs from the similarity solution by a maximum of $8 \%$. It was observed that the largest absolute pressure difference exists at the end of the adiabatic region, at which point the vapor decelerates.

Thermal resistances obtained from Case 1 are provided in Table 3. In Case 1, the thermal resistance of the vapor core was found to be dominant for the heat pipe, at almost $50 \%$ of the overall thermal resistance. This can be attributed to the high thermal conductivity and small thickness of the heat pipe wall, which imposes a negligible impedance on the transfer of heat, along with the larger temperature drop experienced by the vapor. The dominant resistance is that of the condenser external flow. This is expected, since the internal resistances of the heat pipe are dependent on the phase change of the working fluid, and thus have much less influence on the temperature drop.

\section{Case 2: HTHP stepped heat input}

\section{Overview of Case 2:}

- Constant heat rate input of $623 \mathrm{~W}$ stepped up to $770 \mathrm{~W}$ (Cases $2 \mathrm{~A}$ and $\mathrm{B}$ )

- Convective cooling $39 \mathrm{~W} / \mathrm{m}^{2} \mathrm{~K} T_{\infty}=300 \mathrm{~K}$ (Case $2 \mathrm{~A}$ )

- Radiative cooling $\varepsilon=0.85, T_{\text {ref }}=0 \mathrm{~K}$ (Case $2 \mathrm{~B}$ )

- Verified to the numerical simulations of Cao and Faghri [4] and Rice and Faghri [5]

A high temperature heat pipe with a constant heat input of $623 \mathrm{~W}$ was simulated using the transient model until steady-state was attained, at which time the heat input was increased to 770 $\mathrm{W}$. Heat pipe cooling was provided by one of two means: radiation (Case $2 \mathrm{~A}, \varepsilon=0.85$, $T_{r e f}=0 \mathrm{~K}$ ) or convection (Case $2 \mathrm{~B}, \boldsymbol{h}=39 \mathrm{~W} / \mathrm{m}^{2} \mathrm{~K}, T_{\infty}=300 \mathrm{~K}$ ). The computational mesh had 80 cells in the $z$-direction, 10 cells in the radial direction and 20 in the azimuthal direction. The computation time to obtain a steady-state solution was approximately 14 hours for Method 2 (transient) and 8 hours for Method 1 (steady).

Figure 4 shows the vapor temperature of the heat pipe at different times as it transitions to steady-state (the rate of heat addition is equal to rate of heat removal). An instantaneous increase 
in heat input is applied to a heat pipe initally at steady-state (Figure 4a) and is again allowed to reach steady-state operation (Figure $4 \mathrm{c}$ ). Figure $4 \mathrm{~b}$ shows the wall temperature after 10 seconds. A larger vapor temperature drop exists in Figure 4a than in Figure 4c ( $30 \mathrm{~K}$ versus $13 \mathrm{~K}$ ), which implies that the thermal resistance of the vapor core decreases as the heat pipe approaches steady-state operation. A similar trend is apparent for convective cooling (Figure 5), where the temperature drop decreases with time. The temperature drop is larger in Figure 5a (immediately after the increase in heat rate) than in Figure 5c (at steady-state operation), indicating a greater thermal resistance through the vapor core. Pressure drops at steady-state are provided for Case 2 $\mathrm{A}$ and $\mathrm{B}$ in Figure $6 \mathrm{a}$ and $\mathrm{b}$, respectively. The heat pipe in Case $2 \mathrm{~A}$ showed a larger centerline absolute pressure drop when compared to Case $2 \mathrm{~B}$, due to a greater wall temperature difference. Since the heat pipe vapor core is an ideal gas, an increase in the wall temperature drop induces a corresponding change in vapor temperature and thus increases the absolute vapor pressure drop.

In Case $2 \mathrm{~A}$, the largest heat pipe thermal resistances were found to be those in the evaporator. The vapor core ceased to be the largest thermal resistance because of the increase in condenser surface area from Case 1, which allows for a more even distribution of heat (lower end-to-end vapor temperature drop). In Case $2 \mathrm{~B}$, the thermal resistance through the vapor core was further reduced from Case $2 \mathrm{~A}$. This phenomenon is explained by examining the vapor core thermal resistance equation and evaluating it under different operating conditions. By applying the ideal gas equation of state to Equation 25b, we can remove the temperature terms:

$$
\Delta R=\frac{8 L_{\text {eff }}}{\pi R_{g} r_{i}{ }^{4}}\left(\frac{\mu_{v 2} p_{v 2}}{\mathrm{~h}_{f g 2}{ }^{2} \rho_{v 2}{ }^{3}}-\frac{\mu_{v 1} p_{v 1}}{\mathrm{~h}_{f g 1}{ }^{2} \rho_{v 1}{ }^{3}}\right)
$$

where subscripts 1 and 2 denote the states to be compared. The above relation shows a third order inverse dependence between the vapor core thermal resistance and the working fluid density. Since the density is highly dependent on the temperature and pressure of the heat pipe, large variations in thermal resistance can be expected. Using the average properties of Case $2 \mathrm{~A}$ (denoted 1) and Case 2 B (denoted 2) in Equation (21), it can be shown that the thermal resistance increases by a full order of magnitude and that the largest contributors to this effect were due to changes in density and pressure.

The conduction through the wick and wall for Case 1 and Case 2 agreed well with the theoretical calculations (Table 3). The thermal resistance through the evaporator wall was of greater magniture than the condenser wall resistance in both Cases. The evaporator was relatively short in Case 2; since the thermal resistance of the evaporator section is inversely proportional to the evaporator length, a greater thermal resistance was obtained. Similarly, the thermal resistance through the evaporator wick was of the next highest magnitude.

In determination of the interfacial resistances, the thermal accommodation factor was assumed unity. This showed good agreement for Case 1, however, Case 2 A and Case 2 B showed larger variations from the predicted values. In either case, the estimates were still within reasonable agreement. 


\subsection{Low temperature heat pipe (LTHP) validation}

Case 3: LTHP

Overview of Case 3:

- One heater at a constant heat rate input of $97 \mathrm{~W}$ (Case $3 \mathrm{~A})$

- Two heaters each at a constant heat rate input of $98 \mathrm{~W}$ (Case $3 \mathrm{~B}$ )

- Condenser modeled as a constant heat sink equal to the rate of heat input (Case A and B)

- Verified with the numerical results of Rice and Faghri [5]

- Validated with experimental results of by Buchko and Faghri [6]

Low temperature heat pipes (LTHPs) operate in the 200 to $550 \mathrm{~K}$ temperature range and typically use water, ammonia or acetone as working fluids [13]. The LTHP experiment performed by Buchko and Faghri [6] had multiple heat sources; their experimental data was used to verify the current numerical model. This heat pipe differed from previously simulated by incorperating multiple evaportor sections seperated by adiabatic regions (the locations of the evaporator sections are given in Table 1). Since the experimental flow rates and temperatures were not reported by Buchko and Faghri [6], the condensor was modeled as a constant heat sink. Two cases were performed for the low temperature heat pipe: Case A used heater 1 (e1) with an input of $97 \mathrm{~W}$, and Case $3 \mathrm{~B}$ used heaters 1 (e1) and 2 (e2) with an input of $98 \mathrm{~W}$ each. For both cases, the mesh had 138, 7, and 14 cells in the $z$-direction, radial and azimuthal, respectively. Three of the 7 radial cells were in the wick domain, while the remaining were located in the vapor. The reference temperature for each case was obtained from the estimated mean vapor temperature of the experimental results. The properties and dimensions for each case are listed in Table 1. Since a constant heat source(s) and sink were applied as the input and output, the external resistences do not exist and are excluded from those reported in Table 4. The simulation took approximately 4 hours to reach time invariant temperatures.

The evaporator wall-vapor core temperature drop, shown in Figure 7, was approximatly the same when either one heater (97 W heat input) or two heat inputs (98 W, each) were applied. By dividing the evaporator into multiple sections, it was possible to minimize the temperature rise in the heated sections. However, if the heat input is doubled, the condenser wall temperature must decrease to provide further cooling; as such, Case $2 \mathrm{~B}$ was found to have a larger wall temperature drop $(\sim 17 \mathrm{~K})$ than Case $2 \mathrm{~A}(\sim 12 \mathrm{~K})$.

The pressure drops shown in Figure 8 are in good agreement with the similarity solution of Faghri [17], with both solutions demonstrating a pressure drop recovery at the beginning of the condenser. In Case $3 \mathrm{~A}$, less deviation was found compared to the analytically predicted thermal resistance than for Case $3 \mathrm{~B}$ (3.5\% and $11.5 \%$ of the total pressure drop, respectively). This may be attributed to the method used to obtain the empirical vapor core thermal resistance. To 
account for the multiple evaporators and adiabatic sections, an effective length was used to calculate the vapor core thermal resistance. The effective evaporator length was defined as the sum of each individual evaporator length. Furthermore, there may be some heat loss through the adiabatic region between the two heaters; therefore this assumption may underestimate the true thermal resistance.

In the performed LTHP simulations, the vapor core and interfacial thermal resistances can be considered negligible since they are several orders of magnitude smaller than those of the wick or wall (Table 3). The heat pipe wall is relatively thin and made of highly conductive copper, therefore the thermal resistances associated with heat transfer in the wall were found to be negligible, and the wick thermal resistances were the primary impedance to heat transfer.

\subsection{Simulation with channel flow cooling}

The channel flow simulations involved separate cases of heat pipes operating at high and low temperatures with air flow modeled around the condenser wall. The channel flow simulations solve the conjugate heat transfer of the heat pipe and air coolant, and thus did not employ a constant heat transfer coefficient at the surface of the condenser wall. Temperature variations were found from the leading to trailing edge of the heat pipe, depicted in Figure 9. LTHPs with channel flow cooling were investigated in Case 4, while HTHPs were simulated in Case 5. Properties and dimensions are given in Table 1.

\section{Case 4: LTHP channel flow cooling}

Overview of Case 4:

- $\quad$ No condenser fins were included in Cases 4 (A and B)

- 3 condenser fins were included in Cases 4 (C and D)

- A constant heat input of $10 \mathrm{~W}$ heat input with convective cooling was used in Cases 4 (A and C)

- A constant heat input of $20 \mathrm{~W}$ heat input with convective cooling was used in Cases 4 (B and D)

LTHPs were simulated with fins (Cases $4 \mathrm{~B}$ and D) and without fins on the condenser (Cases $\mathrm{A}, \mathrm{C}$ ), under a constant heat input of $10 \mathrm{~W}$ (Cases A and B), which was then doubled to $20 \mathrm{~W}$ in subsequent simulations (Cases $\mathrm{C}$ and $\mathrm{D}$ ). Three evenly-spaced aluminium fins were added to increase the heat transfer area for the cases with condenser fins.

Increasing the heat input from 10 to $20 \mathrm{~W}$ on the unfinned heat pipe resulted in an increased leading-to-trailing edge temperature variation (Figure 10). However, the magnitude of this temperature variation is still small when compared with the overall evaporator to condenser wall temperature drop $(<5 \%)$. A considerable variation in vapor core thermal resistance (Table 5) was observed in most Cases (> 300\%). However, the axial temperature change of the vapor core only differs from the analytically predicted temperature by $1 \cdot 10^{-6} \mathrm{~K}$, which may not be computationally or physically feasible. 
In Case $4 \mathrm{C}$ and Case $4 \mathrm{D}$, the total vapor core thermal resistance was negligible when compared to the wick and wall. The addition of condenser fins did not greatly increase the vapor core thermal resistance because the temperature drop was negligible. Due to the low thermal conductivity of the wall and wick material, the thermal resistances due to conduction dominate. In order to optimize heat pipe operation, the wall material could be changed from stainless steel to copper, increasing heat transfer rates.

\subsubsection{Case 5: HTHP channel flow cooling}

Overview of Case 5:

- No condenser fins were included in Cases 5 (A, B, D, F and H)

- 6 Fins were included in the condenser of Cases 5 (C, E, G and I)

- Constant heat input with constant convective cooling was applied in Cases 5 (B and C)

- Convective heat input with convective cooling was applied in Case 5 (D and E)

- Constant heat input with channel flow cooling was applied in Cases 5 (A, F, and G)

- Convective heat input with channel flow cooling was applied in Cases (H and I)

The external channel flow simulation method was expanded to HTHPs and validated with experimental results of Ivanovski et al. [16]. In order to verify the accuracy of the channel flow model, simulations were performed with a constant convection coefficient at the condenser section, with heat transfer coefficients estimated from the bulk fluid properties of the channel flow cases. This provided predictions for the heat pipe thermal resistances, wall temperature variations, and pressure drops.

Heat was provided to the evaporator in one of two ways: 1) constant heat input (Cases $5 \mathrm{~A}, \mathrm{~B}$, $\mathrm{F}$ and $\mathrm{G}$ ) and 2) convective heat input (Cases $5 \mathrm{D}, \mathrm{E}, \mathrm{H}$ and I). Heat pipes were simulated without condenser fins (Cases A, B, D, F and $\mathrm{H}$ ) and with six evenly spaced condenser fins (Cases C, E, G, and I). Channel flow cooling was included in Cases 5 A, F, G, H and I with a flow velocity intended to match the heat transfer coefficient used in Case 5 B, C, D and E. All heat pipe properties and dimensions are provided in Table 2.

Case $5 \mathrm{~A}$ used the data from Ivanovski et al. [16] to validate the channel flow model using an inlet channel velocity estimated by matching the heat transfer coefficient provided by Cao and Faghri [4]. As an estimate, this showed good agreement with the vapor temperatures from Case 1 (within $\sim 3 \mathrm{~K}$ on average, shown in Figure 11a). The pressure drop in Figure 12a shows that the numerical simulation only deviated from the similarity solution by $10 \%$ of the maximum pressure drop.

A LTHP with constant heat input, convective cooling and no condenser fins was simulated in Case 5 B and compared to a LTHP with 6 condenser fins (Case 5 C). The wall temperature (Figure $11 \mathrm{~b}, \mathrm{c}$ ) was found to decrease with the addition of fins by approximately $70 \mathrm{~K}$. For Case $5 \mathrm{C}$, a larger driving pressure drop was found (Figure 12c) than in Case 5 B, (Figure 12b) at 
$15 \%$ to $11 \%$ of the maximum pressure drop when compared to the similarity solution. This is due to a sudden drop in pressure is experienced in the vicinity of the fins. The finned heat pipe had an $18 \%$ lower external condenser thermal resistance (Table 6) than the un-finned heat pipe under the same conditions. The vapor core thermal resistance, however, was found to be larger for the finned heat pipe. This is due to a decrease in the heat pipe operating temperature which decreased the vapor core density, and increased the thermal resistance.

Heat pipe simulations were performed without fins (Case 5 C) and with fins (Case 5 D) for a convectively cooled and heated heat pipe. The addition of fins reduced the mean wall temperature by about $170 \mathrm{~K}$ (Figure 11e) from the un-finned heat pipe (Figure 11d). Again, a greater vapor pressure drop deviation was found for Case $\mathrm{E}$ due to the presence of external condenser fins ( $5 \%$ higher than Case D). The thermal resistance of the overall system with added fins was $30 \%$ less than the un-finned case (Table 6). The heat transferred with fins was also increased by $30 \%$ from the un-finned heat pipe.

For the convective cooling cases without fins, the thermal resistances of the wick and wall dominate over those of the interface and vapor core. For the finned heat pipe, the thermal resistance through the vapor core becomes of greater concern. In all cases of constant convective cooling, the external condenser thermal resistance was the largest system resistance, and the addition of fins was found to reduce this resistance.

Full simulation of the coolant flow field was performed in Cases A and F-I, and estimates were made for the condenser side heat transfer coefficients based on bulk fluid properties. As a result of the varying heat transfer coefficient in the case of channel flow, larger variations were observed from the empirical correlations of the overall resistances.

Case F used an un-finned heat pipe with a constant heat input and channel flow cooling (heat pipe and flow properties listed in Table 1). The simulation was then repeated with 6 external condenser fins (Case G). Case $5 \mathrm{G}$ showed the largest disagreement in pressure drop with the similarity solution (Figure $14 \mathrm{~b}$ ), of any case (700 $\mathrm{Pa}$ at maximum). This is attributed to the Mach number of the heat pipe being greater than 1 and internal vapor velocity surpassing the sonic limit.

A heat pipe with convective heat input and channel flow cooling was simulated (Case $\mathrm{H}$ ) and the simulation was repeated with 6 condenser fins (Case I). The condenser fins were found to decrease the average wall temperature $(30 \mathrm{~K})$, however, the amount of heat transfer was only increased slightly (11\%).

The variation in wall temperature from the heat pipe leading-to-trailing edge was small for all cases; less than $5 \%$ of the heat pipe overall temperature drop (Figure 13). A comparison between the un-finned heat pipes with constant heat input (Cases $5 \mathrm{C}$ ), and fully simulated channel flow cooling (Case $5 \mathrm{~F}$ ), yielded a variation of approximately $12 \%$ of the overall system thermal resistance. The heat pipe with constant heating and convective cooling with fins (Case 
C) was found to have a lower thermal resistance than without fins (Case B) by about 17\%. In addition, the heat pipe with channel flow cooling was found to have a decreased thermal resistance by approximately $8 \%$ from the heat pipe without fins (Case G). This decrease in fin effectiveness, seen between the two finned cases under constant heat input, may be a result of the fin interaction with the coolant flow. The coolant flow is slowed and the temperature is increased, thus lowering the local heat transfer coefficient. The thermal resistance due to the external hot and cold working fluid at the evaporator/ condenser wall were the greatest thermal resistances due to the large temperature drop, between the heat pipe wall and fluid. The largest internal resistances were those of the heat pipe wall and wick, due to the low thermal conductivity of each. In Case $5 \mathrm{C}, \mathrm{E}$ and $\mathrm{G}$, it was shown that the vapor core thermal resistance was not negligible (as it was in other cases) due to a higher vapor temperature drop, because of the addition of fins. However, the temperature of the heat pipe outer wall was greatly reduced on the condenser side, which decreased the thermal resistance of the system. The resistances of the wick-vapor interface were also significant in Case $5 \mathrm{G}$ due to the high centerline Mach number which causes viscous heating on the boundary and an increased end-to-end temperature difference.

\section{Conclusion}

A working model was developed to simulate high and low temperature heat pipe operation for both transient and steady state modes of operation. In addition, the single domain conjugate problem of coolant flow around a conventional cylindrical heat pipe was also solved without empirical correlations and the dominant thermal resistances were identified. It was proven that in high temperature heat pipe applications, the addition of fins can increase the thermal resistance of the vapor core, due to an increase in the vapor core temperature drop, and thus may be of higher design concern. In lower temperature applications, it was shown that the vapor core temperature does not increase significantly; thus the thermal resistance through the vapor can be neglected.

\section{Acknowledgement}

This material is based upon work supported by the National Science Foundation under Grant Nos. 1435233 (University of Connecticut) and 1435131 (University of Kansas). 


\section{List of Figures}

Figure 1 Heat pipe elements and configuration for a conventional cylindrical heat pipe …….............................18

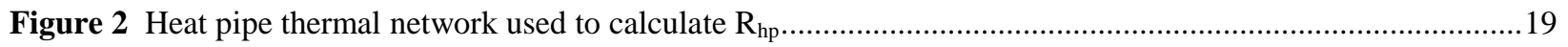

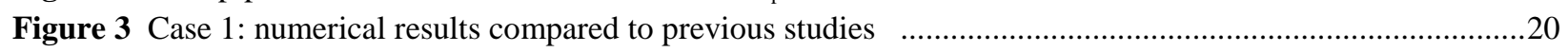

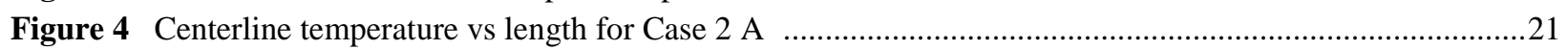

Figure 5 Centerline vapor temperature vs length for Case 2 B ......................................................................22

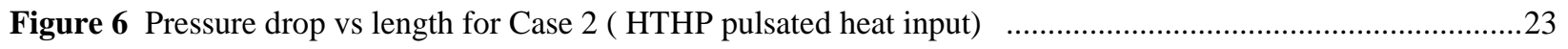

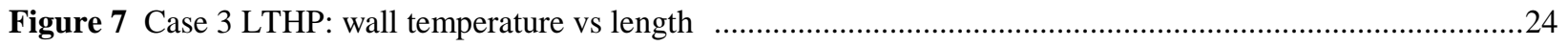

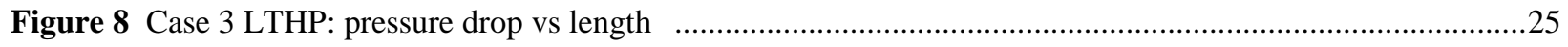

Figure 9 Top view of the solution domain for a heat pipe under channel flow cooling .........................................26

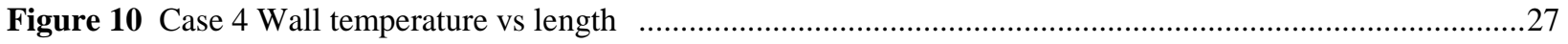

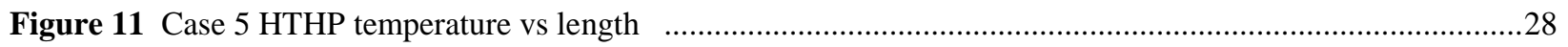

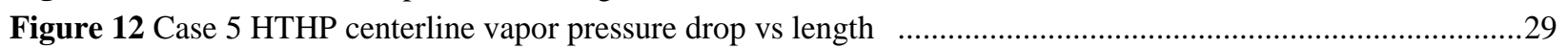

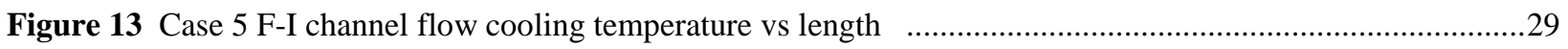

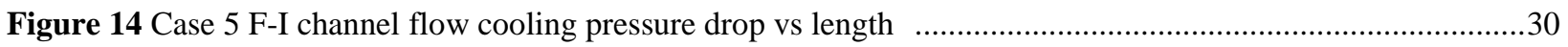




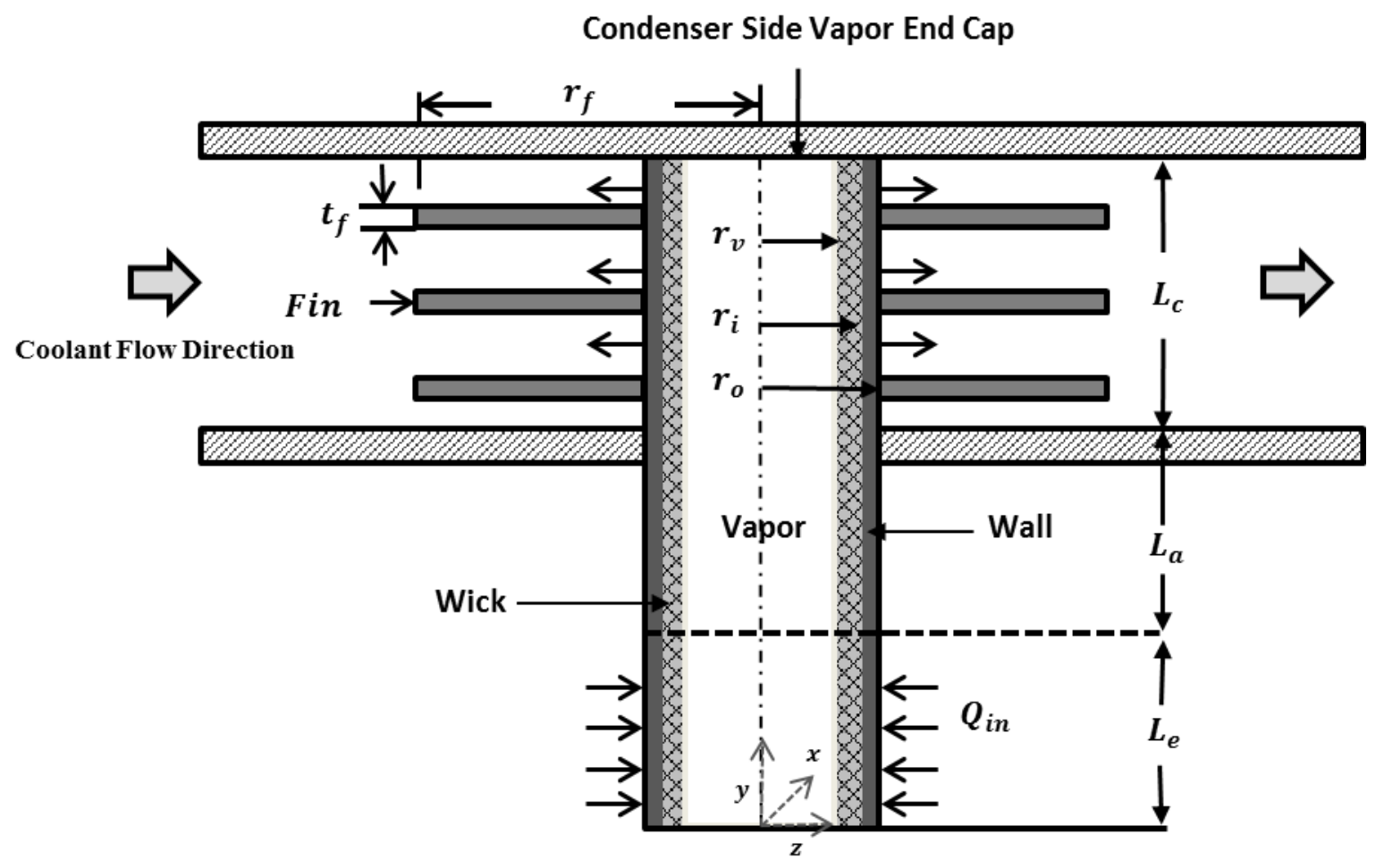

Figure 1 Heat pipe elements and configuration for a conventional vertical cylindrical heat pipe with channel flow across the condenser section. 
$\boldsymbol{R}_{(\boldsymbol{e} / \boldsymbol{c}), \boldsymbol{e x}}$ : External thermal resistance due to heat source / heat sink

$\boldsymbol{R}_{(\boldsymbol{e} / \boldsymbol{c}), \boldsymbol{w}}$ : Radial thermal resistance due to conduction through the evaporator/ condenser wall

$\boldsymbol{R}_{(\boldsymbol{e} / \boldsymbol{c}), \boldsymbol{w} \boldsymbol{k}}$ : Radial thermal resistance due to conduction through the

evaporator/condenser wick $\boldsymbol{R}_{(\boldsymbol{e} / \boldsymbol{c}) \text {,inter }}$ : Radial thermal resistance due to convection at the evaporator/condenser interface

$\boldsymbol{R}_{v}:$ Axial resistance due to the vapor

$\boldsymbol{R}_{\boldsymbol{a}, \boldsymbol{w}}$ : Axial conduction through adiabatic wall

$\boldsymbol{R}_{\boldsymbol{a}, \boldsymbol{w k}}:$ Axial conduction through adiabatic wick

$\boldsymbol{R}_{\boldsymbol{c}, \boldsymbol{f}}$ : External resistance from fins to coolant

Note: if fins are added an

equivalent resistance must be placed on the condenser surface such that $\frac{1}{\boldsymbol{R}_{c, e f f}}=\frac{1}{\boldsymbol{R}_{c, w}}+\frac{\mathbf{1}}{\boldsymbol{R}_{c, f}}$

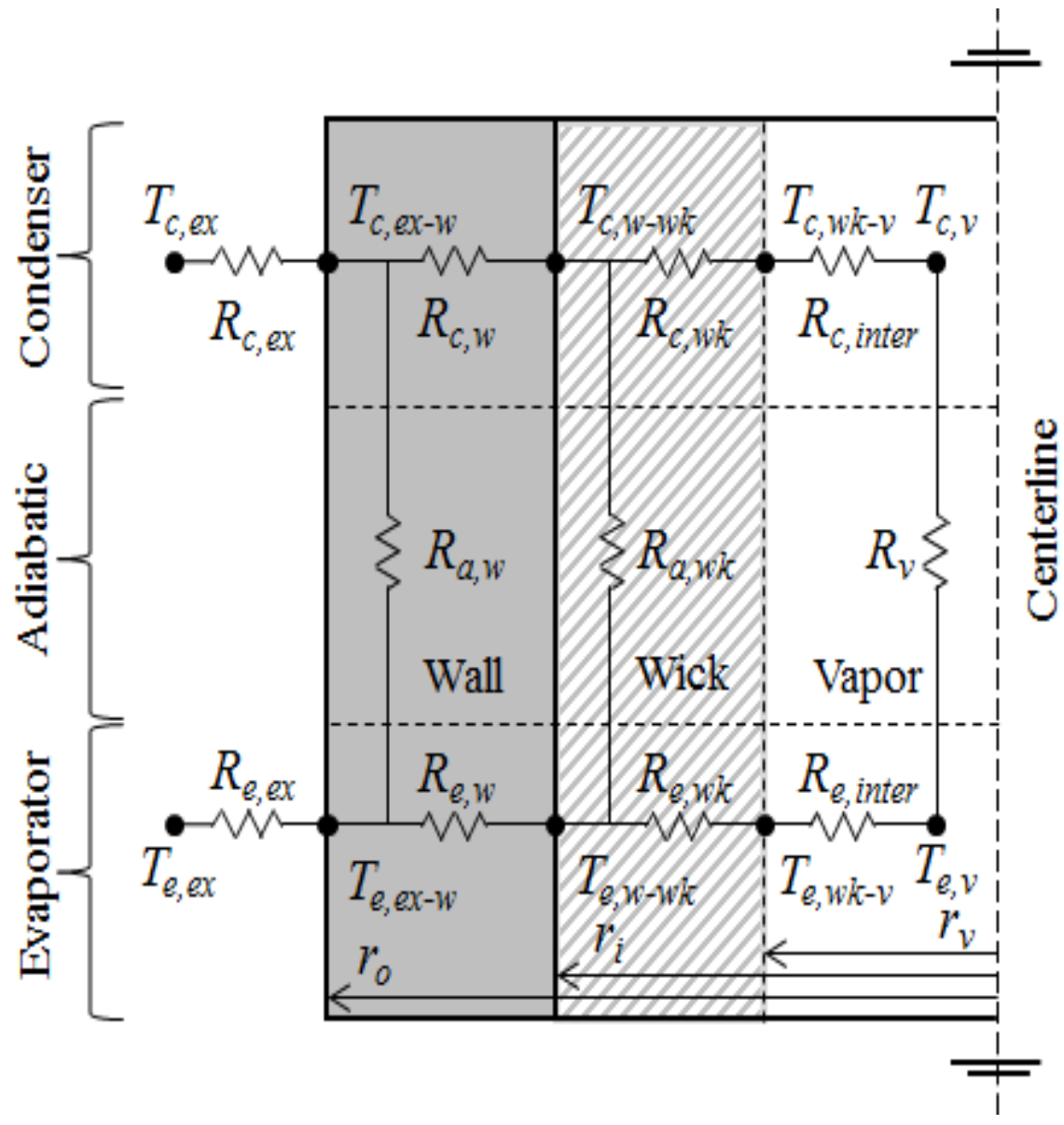

Figure 2 Heat pipe thermal network used to calculate $R_{h p}$. 

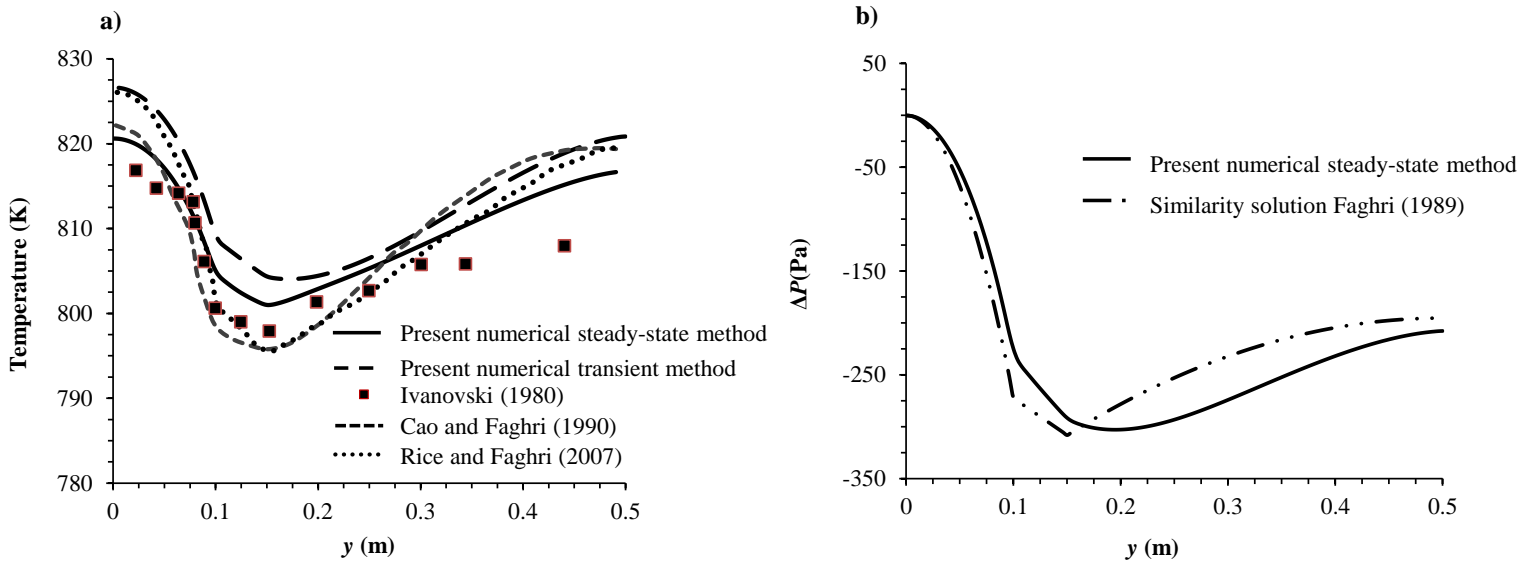

Figure 3 Case 1: Numerical results compared to previous studies a) Centerline vapor temperature vs. length $\boldsymbol{b})$ centerline vapor pressure drop vs. length. 
a)

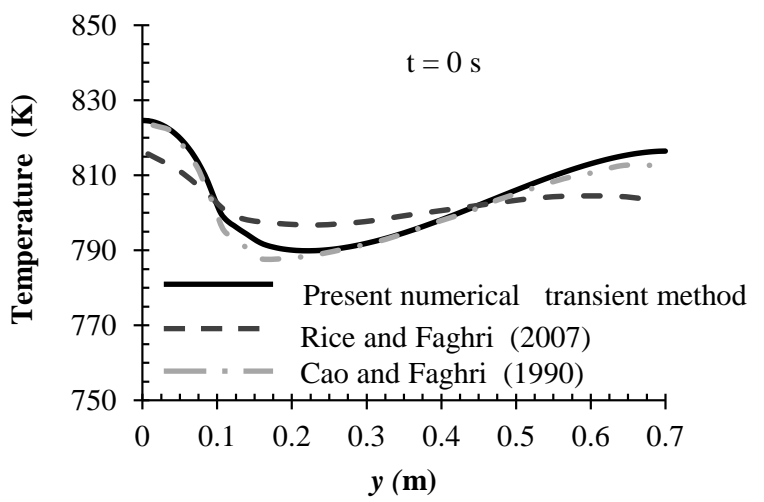

b)

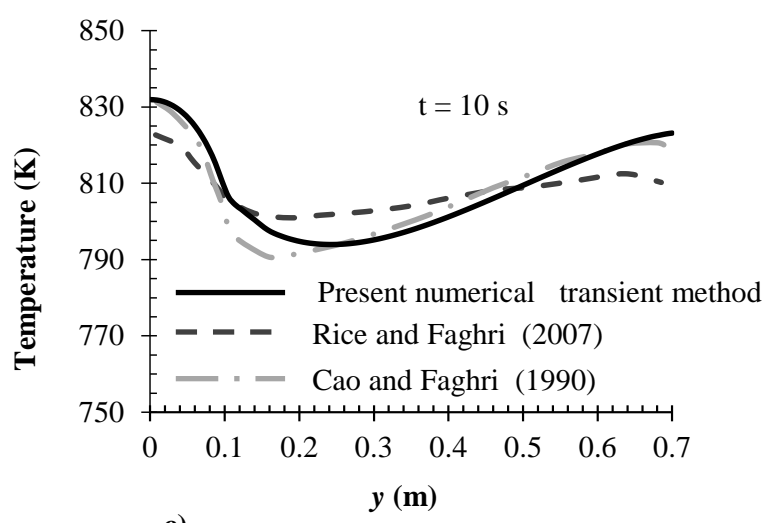

c)

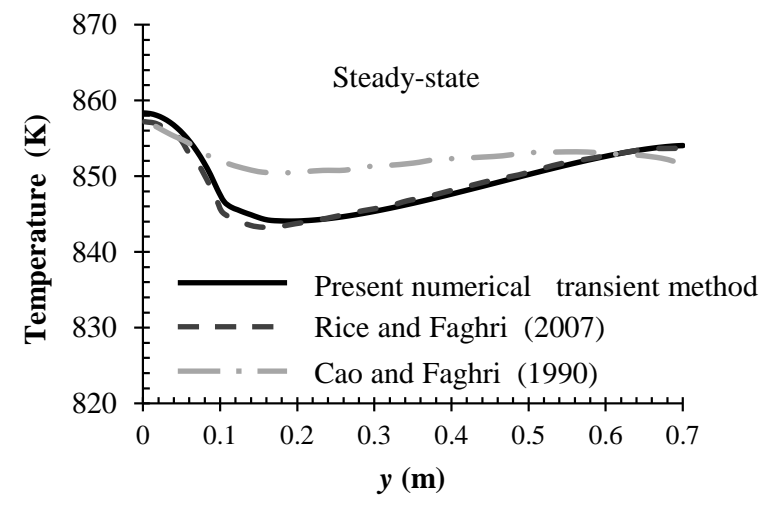

Figure 4 Centerline temperature vs. length for Case 2 A (HTHP pulsated heat input, radiative cooling) at multiple intervals steps $\boldsymbol{a}$ ) $t=0$ seconds after heat input increase $\boldsymbol{b}) t=10$ seconds after heat input increase $\boldsymbol{c})$ steady-state $\left(Q_{e}=Q_{c}\right)$. 
a)
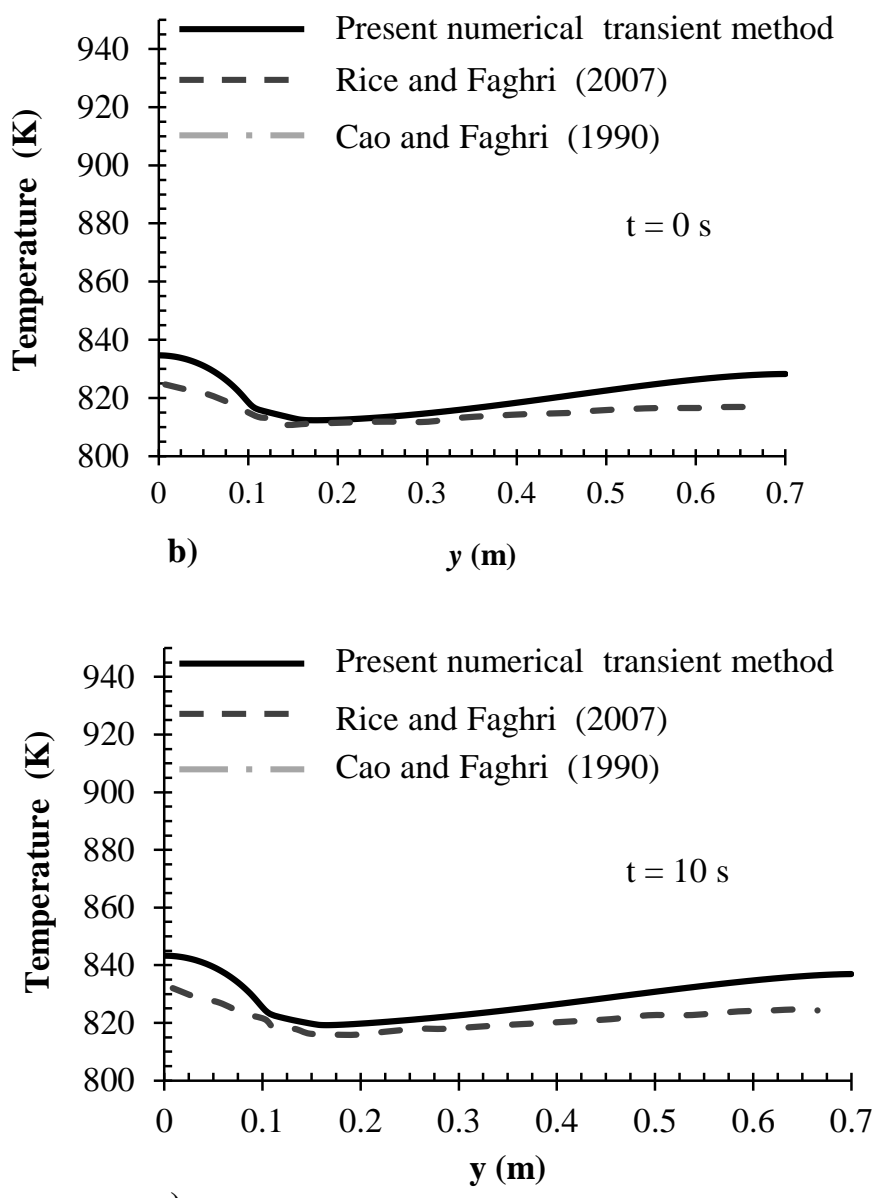

c)

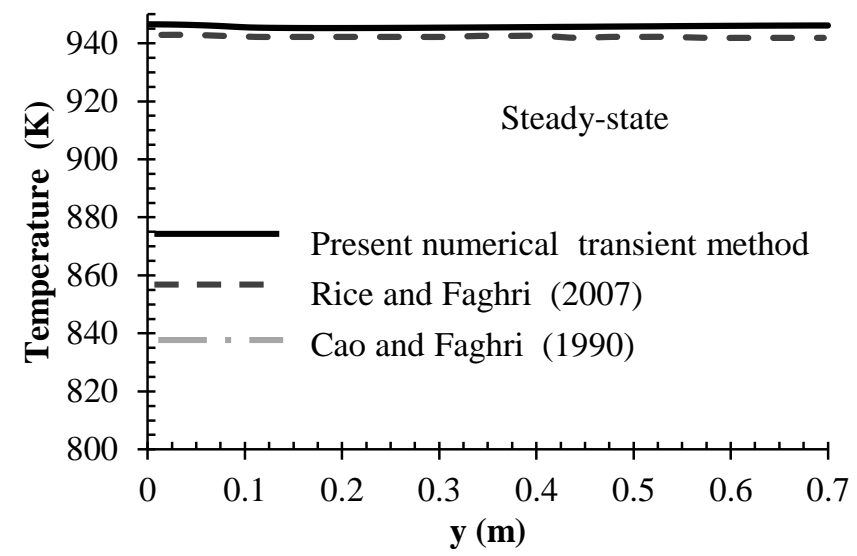

Figure 5 Centerline vapor temperature vs. length for Case 2 B (HTHP pulsated heat input, convective cooling) at multiple time intervals a) $t=0$ seconds after heat input increase $\boldsymbol{b}) t=10$ seconds after heat input increase c) steady-state $\left(Q_{e}=Q_{c}\right)$. 
a)

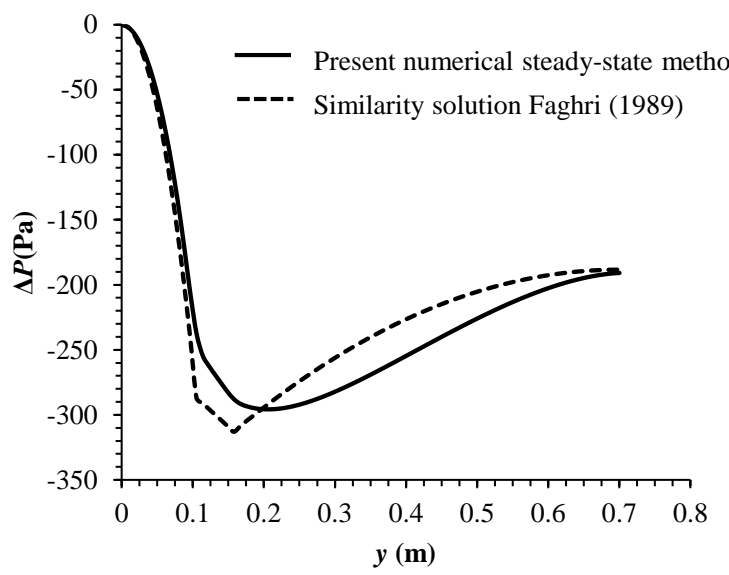

b)

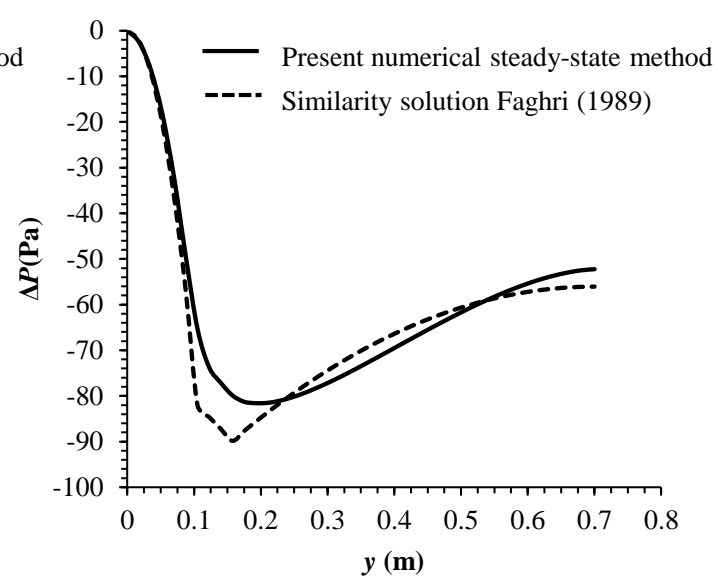

Figure 6 Pressure drop vs. length for Case 2 ( HTHP pulsated heat input) a) Case 2 A steady state radiative cooling $\boldsymbol{b}$ ) Case $2 \mathrm{~B}$ steady state convective cooling. 
a)

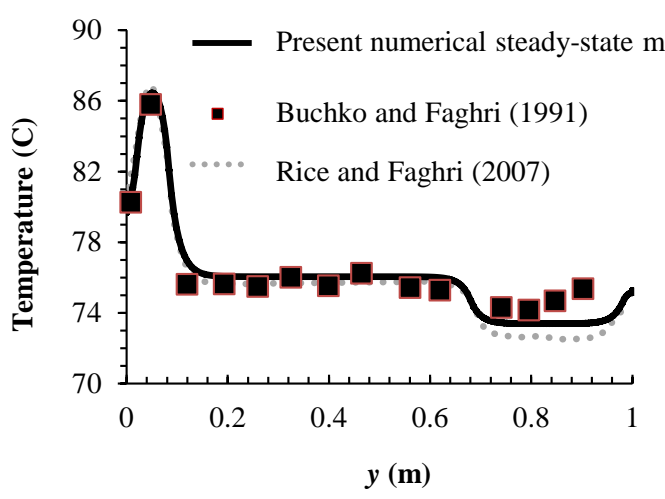

b)

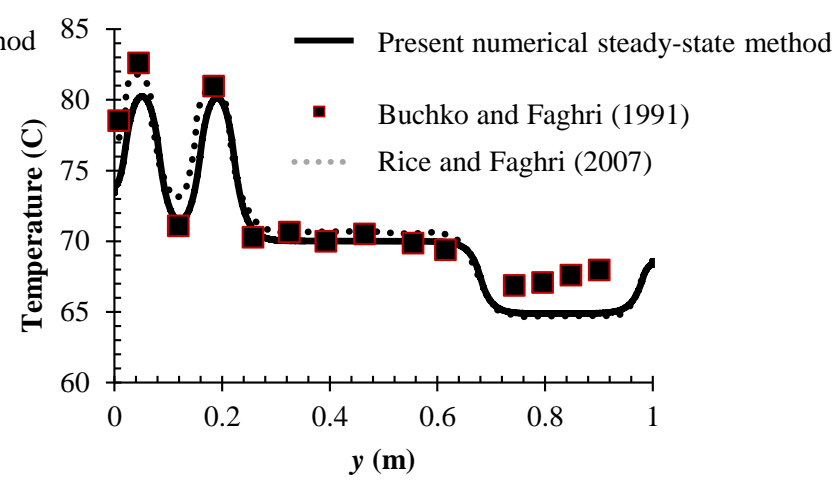

Figure 7 Case 3 (LTHP): wall temperature vs. length a) Case 3 A: with evaporator 1 active, 97 Wb) Case 3 B: with evaporators 1 and 2 active, $98 \mathrm{~W}$ each. 
a)

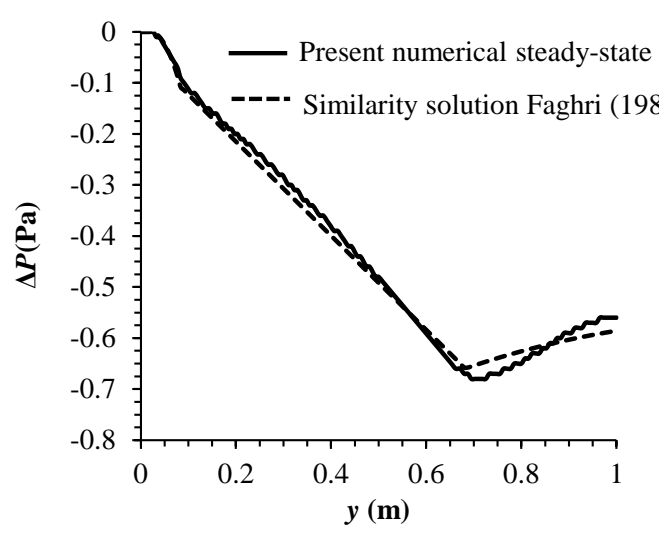

b)

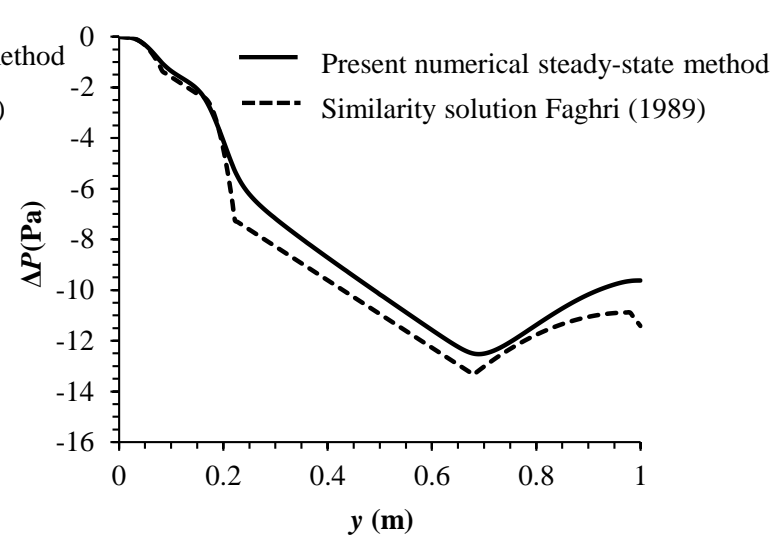

Figure 8 Case 3 (LTHP): pressure drop vs. length a) Case 3 A: with evaporator 1 active, $97 \mathrm{~W}$ b) Case 3 B: with evaporators 1 and 2 active, $98 \mathrm{~W}$ each. 


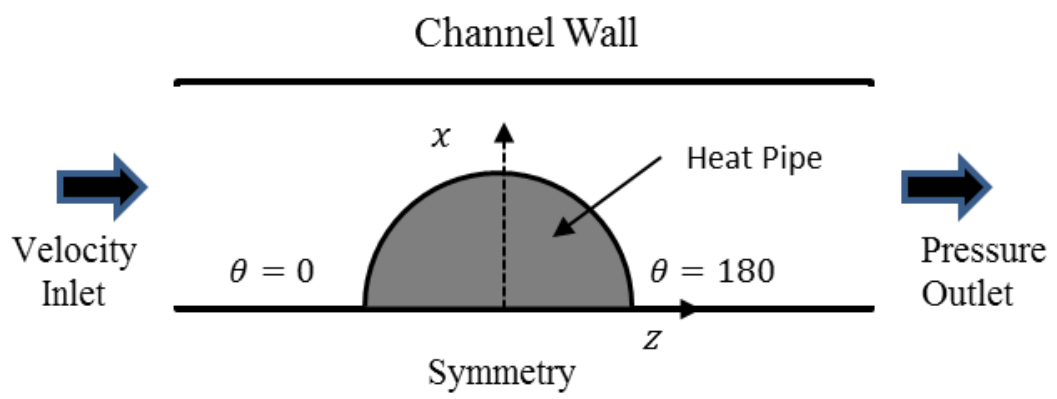

Figure 9 Solution domain (in the xz, plane) for a heat pipe with channel flow cooling. 
a)
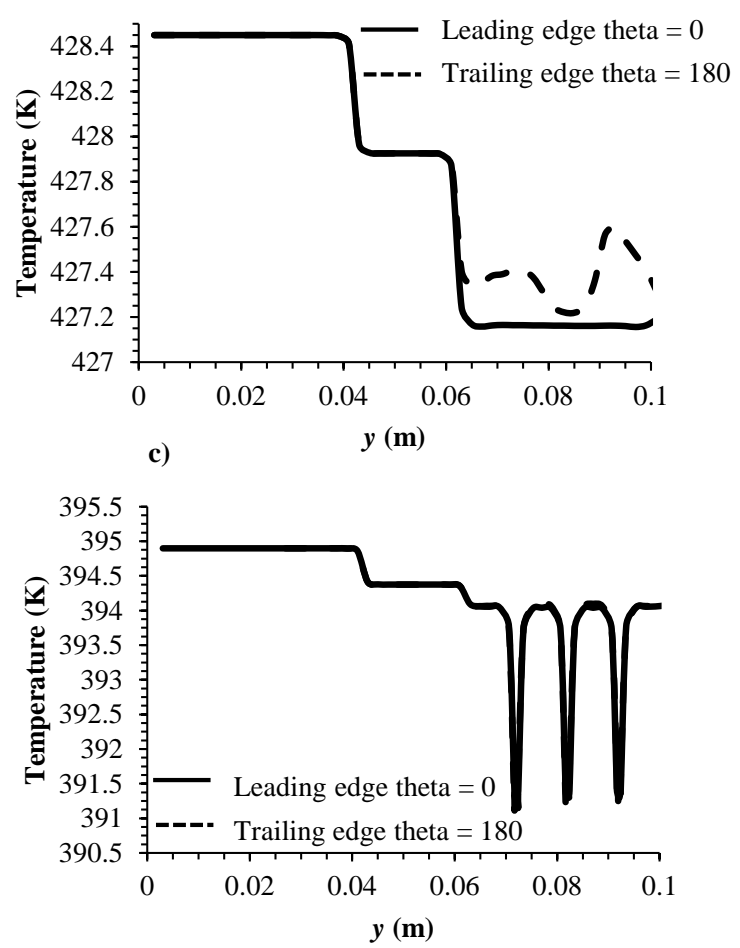

b)
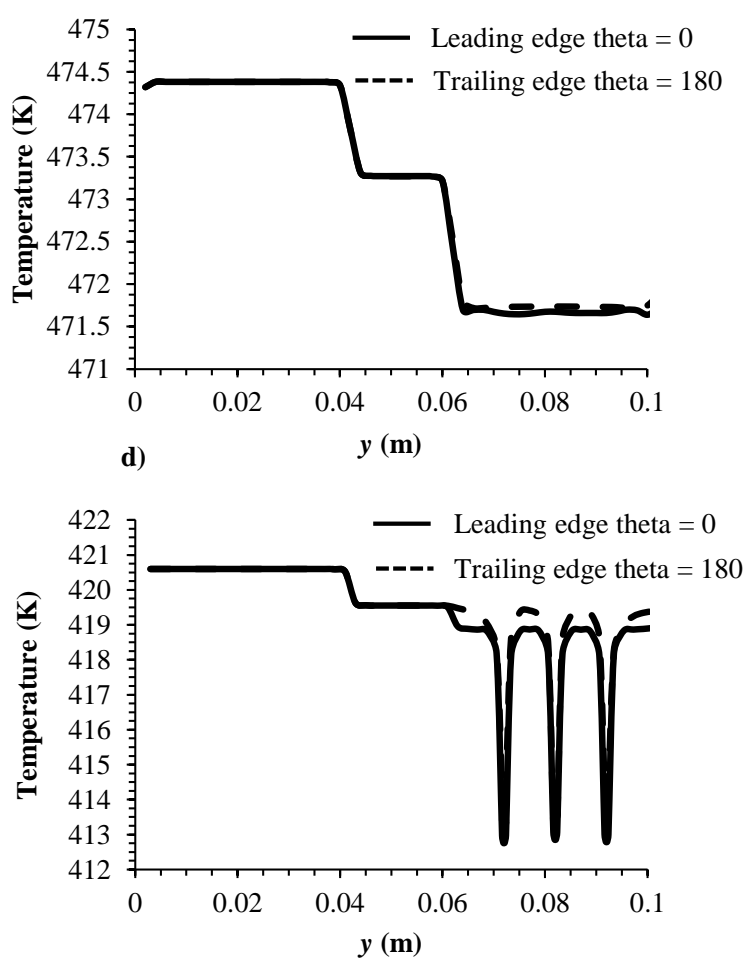

Figure 10 Case 4: Wall temperature vs. length a) Case 4 A: 10 W heat input without fins b) Case 4 B: 20 W heat input without fins c) Case 4 C: 10 W heat input with 3 condenser fins d) Case 4 D: 20 Wheat input with 3 condneser fins. 

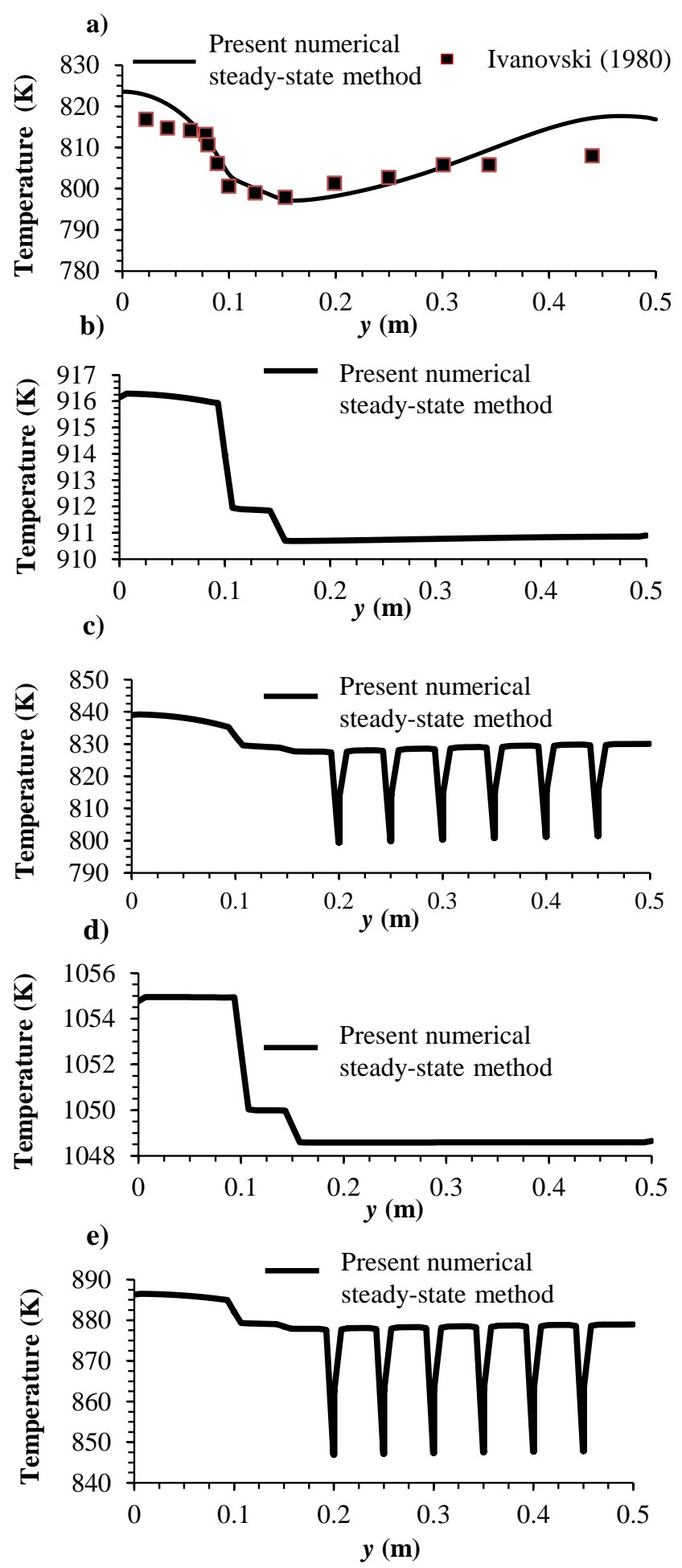

Figure 11 Case $5($ HTHP) Length vs. centerline vapor temperature for: a) Case 5 A: Channel flow cooling, length vs. wall temperature for: $\boldsymbol{b})$ Case 5 B constant heat input with fins c) Case 5 $C$ constant heat input without fins d) Case 5 D convective heat input without fins e) Case $5 E$ convective heat input with fins. 


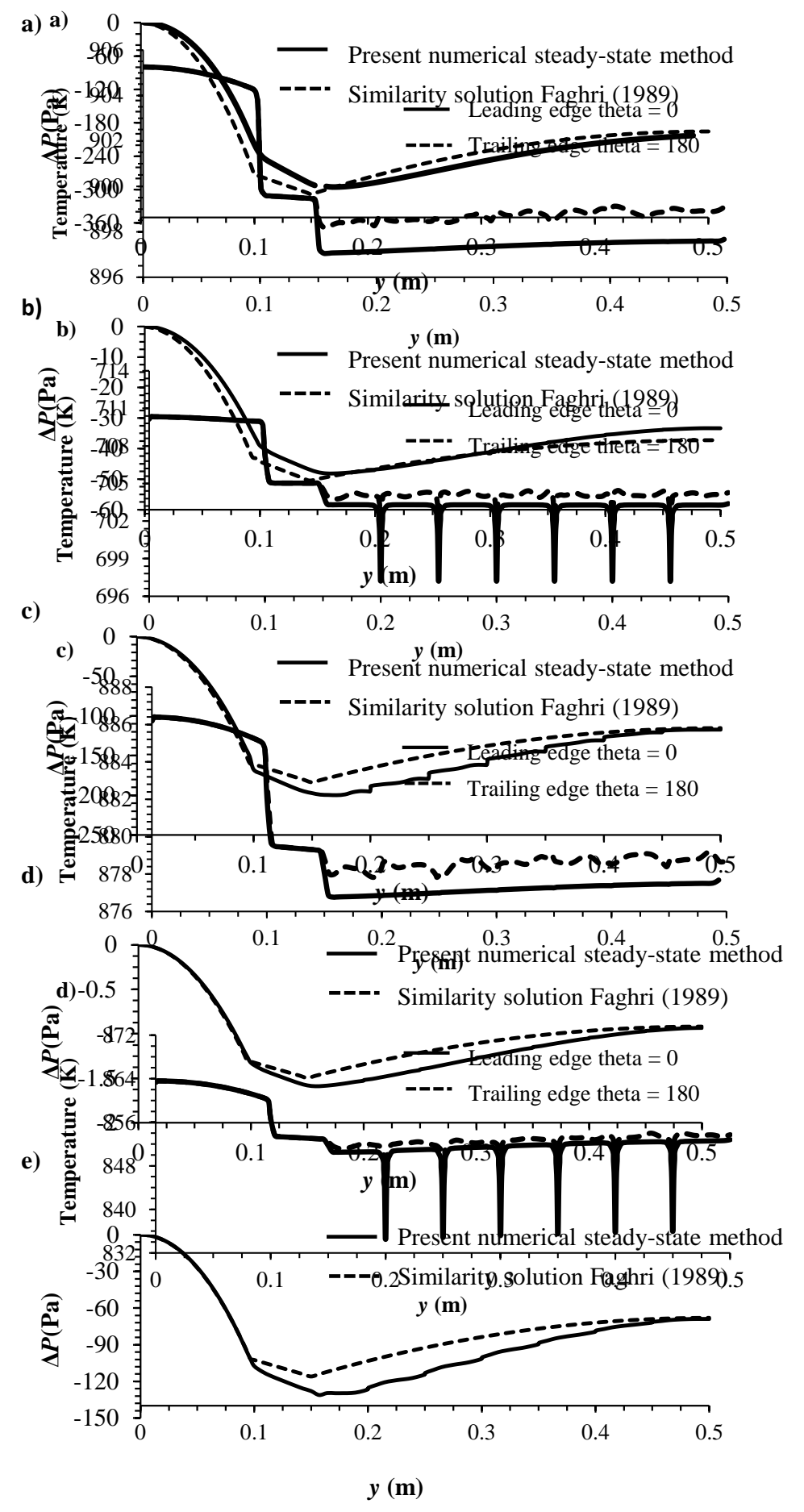

Figure 12 Case 5 (HTHP) Centerline vapor pressure drop vs. length a) Case 5 A channel flow cooling b) Case 5 B constant heat input with fins c) Case 6 C constant heat input without fins d) Case 5 D convective heat input without fins $\boldsymbol{e}$ ) Case 5 E convective heat input with fins.

Figure 13 Case 5 F-I: Channel flow cooling temperature vs. length a) Case 5 F constant heat input no fins $\boldsymbol{b})$ Case $5 \mathrm{G}$ constant heat input 6 fin) $c$ ) Case $5 \mathrm{H}$ convective heat input, no fins d) Case 5 I convective input, 6 fins. 


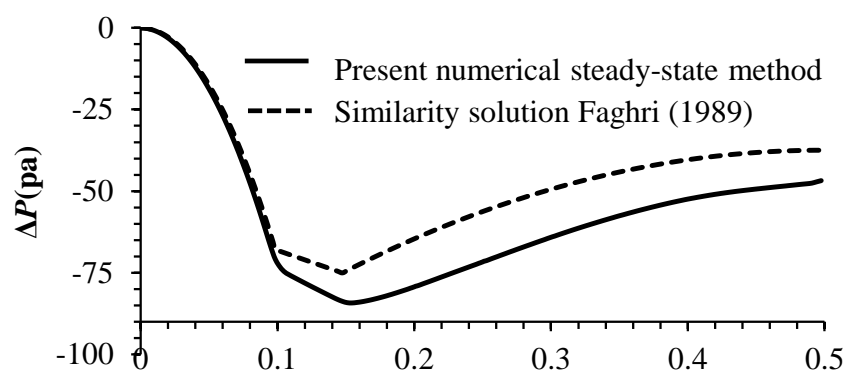

b)

$$
y \text { (m) }
$$

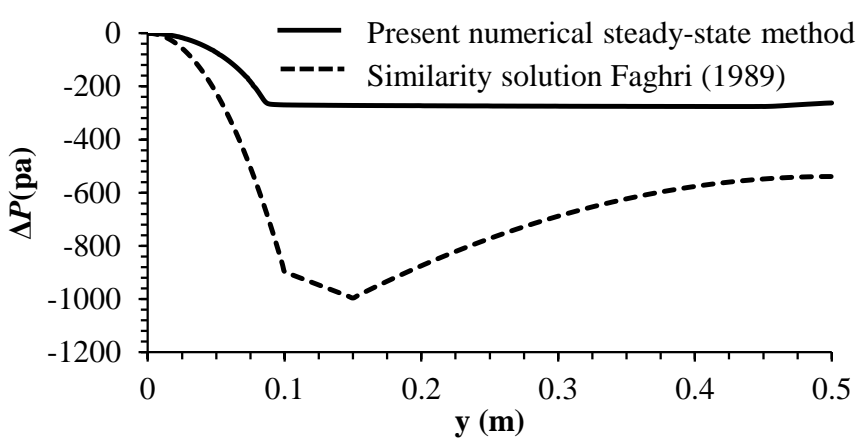

c)
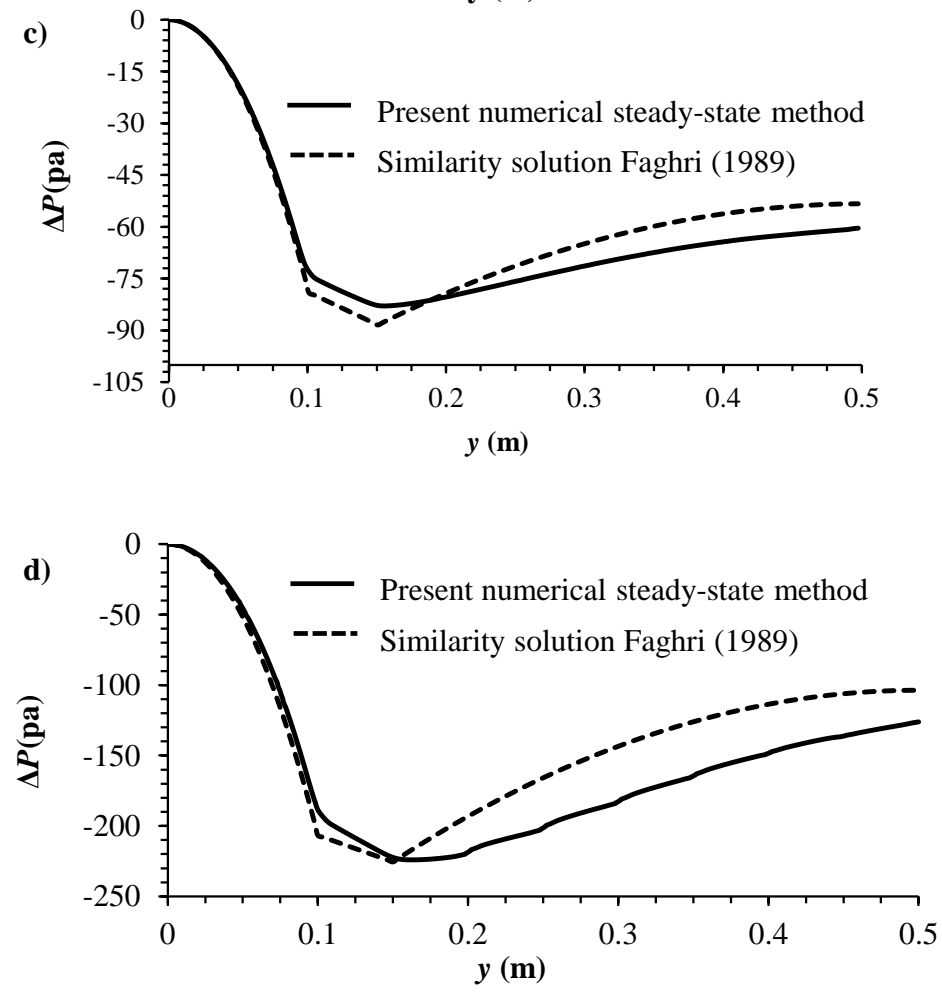

Figure 14 Case 5 F-I: Channel flow cooling pressure drop vs. length a) Case 5 F constant heat input no fins $\boldsymbol{b}$ ) Case $5 \mathrm{G}$ constant heat input 6 fins $\boldsymbol{c}$ ) Case $5 \mathrm{H}$ convective heat input, no fins $\boldsymbol{d}$ ) Case 5 I convective input, 6 fins. 


\section{List of Tables}

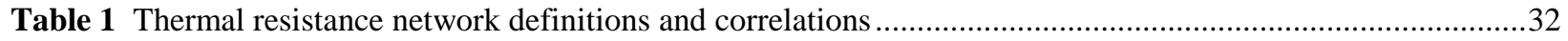

Table 2 Heat pipe, properties, dimensions and operating conditions for five the five case simulated .......................33

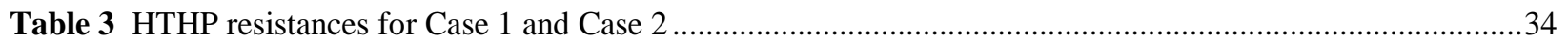

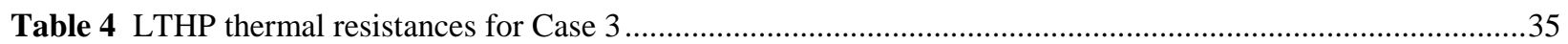

Table 5 LTHP with channel flow cooling thermal resistances for Case 4 .........................................................36

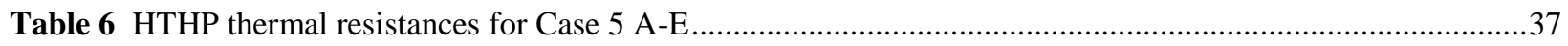

Table 7 HTHP with channel flow cooling thermal resistances for Case 5 F-I .......................................................38 
Table 1 Thermal resistance network definitions and correlations

\begin{tabular}{|c|c|c|c|}
\hline Equation \# & Resistance & Numerical (a) & Analytical/Empirical (b) \\
\hline (20) & $R_{e, e x}$ & $\frac{T_{e, e x}-T_{e, e x-w}}{Q_{e, e x}}$ & convection: $\frac{1}{A_{e, o} h^{*}}$ \\
\hline \multirow[t]{2}{*}{ (21) } & \multirow{2}{*}{$R_{c, e x}$} & \multirow{2}{*}{$\frac{T_{c, e x}-T_{c, e x-w}}{Q_{c, e x}}$} & $\begin{array}{cc}\text { convection: } & \text { radiation: } \\
1 & 1 \\
\end{array}$ \\
\hline & & & $\overline{A_{c, o} h^{*}} \quad \overline{A_{c, o}\left(\varepsilon \sigma\left(T_{c, e x}{ }^{2}+T_{s u r}{ }^{2}\right)\left(T_{c, e x}+T_{s u r}\right)\right)}$ \\
\hline (22) & $R_{e, w}$ & $\frac{T_{e, e x-w}-T_{e, w-w k}}{Q_{e, w}}$ & $\frac{\ln \left(r_{o} / r_{i}\right)}{2 \pi k_{w} L_{e}}$ \\
\hline \multirow[t]{2}{*}{ (23) } & & $T_{e, w-w k}-T_{e, w k-v}$ & $\underline{\ln \left(r_{i} / r_{v}\right)}$ \\
\hline & $R_{e, w k}$ & $\frac{e, w-w k}{Q_{e, w k}}$ & $\overline{2 \pi k_{w k} L_{e}}$ \\
\hline \multirow[t]{2}{*}{ (24) } & & & 1 \\
\hline & $R_{e, \text { int } e r}$ & $\frac{T_{e, w k-v}-T_{e, v}}{Q_{e, \text { inter }}}$ & $\overline{A_{e, i}\left(\frac{2 \alpha}{2-\alpha}\right)\left(\frac{h_{f g}^{2} \rho_{v}}{T_{v}}\right) \sqrt{\frac{1}{2 \pi R_{g} T_{v}}\left(1-\frac{p_{v}}{2 \rho_{v} h_{f g}}\right)}}$ \\
\hline (25) & $R_{v}$ & $\frac{T_{e, v}-T_{c, v}}{Q_{v}}$ & $\frac{8 \mathrm{R}_{g} \mu_{v} T_{v}^{2}}{\pi h_{f g}^{2} P_{v} \rho_{v}}\left[\frac{\left(L_{c}+L_{e}\right) / 2+L_{a}}{r_{i}^{4}}\right]$ \\
\hline \multirow[t]{2}{*}{ (26) } & & & 1 \\
\hline & $R_{c, \text { inter }}$ & $\frac{T_{c, v}-T_{c, w k-v}}{Q_{c, \text { int } e r}}$ & $\overline{A_{c, i}\left(\frac{2 \alpha}{2-\alpha}\right)\left(\frac{h_{f g}^{2} \rho_{v}}{T_{v}}\right) \sqrt{\frac{1}{2 \pi R_{g} T_{v}}}\left(1-\frac{p_{v}}{2 \rho_{v} h_{f g}}\right)}$ \\
\hline (27) & $R_{c, w k}$ & $\frac{T_{c, w k-v}-T_{c, w-w k}}{Q_{c, w k}}$ & $\frac{\ln \left(r_{i} / r_{v}\right)}{2 \pi k_{w k} L_{c}}$ \\
\hline (28) & $R_{c, w}$ & $\frac{T_{c, w k-w}-T_{c, e x-w}}{Q_{c, w}}$ & $\frac{\ln \left(r_{o} / r_{i}\right)}{2 \pi k_{w} L_{c}}$ \\
\hline (29) & $R_{a, w}$ & $\frac{T_{e, e x-w}-T_{c, e x-w}}{Q_{a, w}}$ & $\frac{L_{a}}{\pi k_{w}\left(r_{o}^{2}-r_{i}^{2}\right)}$ \\
\hline (30) & $R_{a, w k}$ & $\frac{T_{e, w-w k}-T_{c, w-w k}}{Q_{a, w k}}$ & $\frac{L_{a}}{\pi k_{w k}\left(r_{i}^{2}-r_{v}^{2}\right)}$ \\
\hline
\end{tabular}

* The heat transfer coefficient is assumed in the case of a constant convection boundary but calculated from flow properties in the case of channel flow cooling. In most cases the adiabatic thermal resistances were neglected since they are large and do not impede the phase change of the working fluid which is the area of interest.

** Equation letter (a) denotes the numerical while (b) denotes analytical/empirical. 
Table 2 Heat pipe, properties, dimensions and operating conditions for Cases 1-5

\begin{tabular}{|c|c|c|c|c|c|}
\hline & $\begin{array}{l}\text { Case 1: HTHP steady } \\
\text { state operation }\end{array}$ & $\begin{array}{l}\text { Case 2: HTHP stepped } \\
\text { heat input }\end{array}$ & Case 3: LTHP validation & $\begin{array}{l}\text { Case 4: LTHP channel } \\
\text { flow cooling }\end{array}$ & $\begin{array}{c}\text { Case 5: HTHP with and } \\
\text { without channel flow } \\
\text { cooling }\end{array}$ \\
\hline Property /dimension & \multicolumn{5}{|c|}{ Value } \\
\hline Working fluid & Sodium & Sodium & Water & Water & Sodium \\
\hline$k_{v}(\mathrm{~W} / \mathrm{mK})$ & 0.0406 & 0.0406 & 0.02161 & 0.0261 & 0.0406 \\
\hline$\mu_{v}\left(\mathrm{~N}-\mathrm{s} / \mathrm{m}^{2}\right)$ & $2.01 \mathrm{e}-5$ & $2.01 \mathrm{e}-5$ & $1.34 \mathrm{e}-05$ & $1.34 \mathrm{e}-05$ & $2.01 \mathrm{e}-5$ \\
\hline$h_{\mathrm{fg}}(\mathrm{kJ} / \mathrm{kg})$ & 4131 & 4131 & 2256 & 2256 & 4131 \\
\hline$r_{v}(\mathrm{~m})$ & 0.0070 & 0.0070 & 0.01025 & 0.0040 & 0.0070 \\
\hline$r_{i}(\mathrm{~m})$ & 0.0075 & 0.0080 & 0.01100 & 0.0045 & 0.0075 \\
\hline$r_{o}(\mathrm{~m})$ & 0.0085 & 0.0090 & 0.01270 & 0.0050 & 0.0085 \\
\hline$L_{e}(\mathrm{~m})$ & 0.1000 & 0.1050 & 0.06350 & 0.0400 & 0.100 \\
\hline $\begin{array}{l}\text { Heater starting locations } \\
\text { e1 }(\mathrm{m}) \\
\text { e2 (m) } \\
\text { e3 (m) } \\
\text { e4 (m) }\end{array}$ & NA & NA & $\begin{array}{l}0.0200 \\
0.1588 \\
0.2976 \\
0.4364\end{array}$ & NA & NA \\
\hline$L_{a}(\mathrm{~m})$ & 0.05 & 0.0525 & NA & 0.0200 & 0.050 \\
\hline$L_{c}(\mathrm{~m})$ & 0.35 & 0.5425 & 0.30000 & 0.0400 & 0.350 \\
\hline Condenser starting location (m) & NA & NA & 0.68 & NA & NA \\
\hline Wall & NA & Stainless steel & Copper & Stainless steel & Stainless Steel \\
\hline$k_{w}(\mathrm{~W} / \mathrm{mK})$ & 35 & 21.7 & 387.6 & 16 & 35 \\
\hline$\rho_{w / w k}\left(\mathrm{~kg} / \mathrm{m}^{3}\right)$ & 8030 & 8030 & 8978 & 8030 & 8030 \\
\hline $\mathrm{cp}_{w / w k}(\mathrm{~kJ} / \mathrm{kgK})$ & 502.48 & 502.48 & 381 & 508 & 502.48 \\
\hline$k_{w k}(\mathrm{~W} / \mathrm{mK})$ & 35 & 45 & 1.38 & 16 & 35 \\
\hline Fin material & NA & NA & NA & Aluminum & Aluminum \\
\hline$r_{f}(\mathrm{~m})$ & NA & NA & NA & 0.015 & 0.015 \\
\hline$k_{f}(\mathrm{~W} / \mathrm{mK})$ & NA & NA & NA & 16 & 16 \\
\hline$\rho_{f}\left(\mathrm{~kg} / \mathrm{m}^{3}\right)$ & NA & NA & NA & 8030 & 8030 \\
\hline $\mathrm{cp}_{f}(\mathrm{~kJ} / \mathrm{kgK})$ & NA & NA & NA & 508 & 508 \\
\hline Heat input & $\begin{array}{l}\text { Constant heat rate: } \\
560 \mathrm{~W}\end{array}$ & $\begin{array}{l}\text { Constant heat rate: } \\
\text { Initial input } 623 \mathrm{~W} \\
\text { Step increase } 770 \mathrm{~W}\end{array}$ & $\begin{array}{l}\text { Constant heat rate: } \\
\text { Case } 3 \mathrm{~A} \text { : } \\
\text { e1: } 97 \mathrm{~W} \\
\text { Case } 3 \mathrm{~B} \text { : } \\
\text { e1: } 98 \mathrm{~W} \\
\text { e2: } 98 \mathrm{~W}\end{array}$ & $\begin{array}{l}\text { Constant heat rate: } \\
\text { Cases } 4 \text { A.C: } 10 \mathrm{~W} \\
\text { Cases } 4 \text { B,D : } 20 \mathrm{~W}\end{array}$ & $\begin{array}{c}\text { Constant heat rate: } \\
\text { Cases } 5 \mathrm{~A}, \mathrm{~B}, \mathrm{C}, \mathrm{F}, \mathrm{G} \\
560 \mathrm{~W} \\
\text { Convective input: } \\
\text { Cases } 5 \mathrm{D}, \mathrm{E}, \mathrm{H}, \mathrm{I} \\
T_{\infty}=1000 \mathrm{~K} \\
\mathbf{h}=1000 \mathrm{~W} / \mathrm{m}^{2} \mathrm{~K}\end{array}$ \\
\hline Heat output & $\begin{array}{l}\text { Convection coefficient: } \\
\left(58.5 \mathrm{~W} / \mathrm{m}^{2} \mathrm{~K}\right) \\
T_{\infty}=300 \mathrm{~K}\end{array}$ & $\begin{array}{l}\text { Radiation: } \\
\text { Case } 2 \mathrm{~A} \\
T_{r e f}=0 \mathrm{~K} \\
\varepsilon=0.85\end{array}$ & Constant heat sink & $\begin{array}{l}\text { No Fins: Cases } 4 \text { A, C } \\
\text { Fins: Cases } 4 \text { B, D } \\
\text { Channel flow: }\end{array}$ & $\begin{array}{l}\text { No Fins: Cases } 5 \text { A, B, } \\
\text { D, F, H } \\
\text { Fins: Cases } 5 \text { C, E, G, I } \\
\text { Channel flow: }\end{array}$ \\
\hline & & $\begin{array}{l}\text { Convection: } \\
\text { Case } 2 \mathrm{~B} \\
39 \mathrm{~W} / \mathrm{m}^{2} \mathrm{~K} \\
T_{\infty}=300 \mathrm{~K}\end{array}$ & & $\begin{array}{l}\text { All Cases } \\
\text { Inlet velocity } \\
10 \mathrm{~m} / \mathrm{s} \\
\text { Inlet temperature } \\
373 \mathrm{~K}\end{array}$ & $\begin{array}{l}\text { Inlet velocity } \\
\text { Case } 5 \mathrm{~A}: 5.13 \mathrm{~m} / \mathrm{s} \\
\text { Cases } 5 \mathrm{~F}, \mathrm{G}, \mathrm{H}, \mathrm{I}: 3 \mathrm{~m} / \mathrm{s} \\
\text { Convection: } \\
\text { Cases } 5 \mathrm{~B}, \mathrm{C}, \mathrm{D}, \mathrm{E} \\
T_{\infty}=300 \mathrm{~K} \\
\mathbf{h}=40 \mathrm{~W} / \mathrm{m}^{2} \mathrm{~K}\end{array}$ \\
\hline
\end{tabular}


Table 3 HTHP resistances for Case $1 \&$ Case 2

Case 1: HTHP under steady state operation

\begin{tabular}{|c|c|c|c|c|c|c|c|c|c|c|}
\hline Resistance (W/K) & $R e, w$ & $R e, w k$ & Re,inter & $R v$ & $R c, w$ & $R c, w k$ & Rc,inter & $R c, e x$ & $R h p$ & Rtot \\
\hline Empirical/analytical & $5.69 \mathrm{E}-03$ & $3.14 \mathrm{E}-03$ & $2.56 \mathrm{E}-03$ & $1.30 \mathrm{E}-02$ & $1.63 \mathrm{E}-03$ & $8.96 \mathrm{E}-04$ & 7.31E-04 & 0.915 & $2.82 \mathrm{E}-02$ & 0.943 \\
\hline Numerical & 5.64E-03 & $3.10 \mathrm{E}-03$ & $2.41 \mathrm{E}-03$ & $1.05 \mathrm{E}-02$ & $1.61 \mathrm{E}-03$ & 8.89E-04 & $1.03 \mathrm{E}-03$ & 0.919 & $2.52 \mathrm{E}-02$ & 0.944 \\
\hline$\%$ Difference & $<1 \%$ & $\sim 1 \%$ & $6 \%$ & $19 \%$ & $<1 \%$ & $<1 \%$ & $41 \%$ & $<1 \%$ & $11 \%$ & $<1 \%$ \\
\hline \multicolumn{5}{|c|}{ Heat input (W) } & \multicolumn{6}{|c|}{560} \\
\hline
\end{tabular}

Case 2 A: HTHP with pulsated heat input and radiative cooling at steady-state operation

\begin{tabular}{|c|c|c|c|c|c|c|c|c|c|c|}
\hline Resistance (W/K) & $R e, w$ & $R e, w k$ & Re,inter & $R v$ & $R c, w$ & $R c, w k$ & Rc,inter & $R c, e x$ & $R h p$ & Rtot \\
\hline Numerical & $8.18 \mathrm{E}-03$ & 4.47E-03 & $1.28 \mathrm{E}-03$ & $3.95 \mathrm{E}-03$ & $1.58 \mathrm{E}-03$ & $8.66 \mathrm{E}-04$ & $2.69 \mathrm{E}-04$ & 0.715 & $2.06 \mathrm{E}-02$ & 0.735 \\
\hline$\%$ Difference & $<1 \%$ & $<1 \%$ & $75 \%$ & $5 \%$ & $<1 \%$ & $<1 \%$ & $90 \%$ & $<1 \%$ & $3 \%$ & $<1 \%$ \\
\hline \multicolumn{5}{|c|}{ Heat input (W) } & \multicolumn{6}{|c|}{770} \\
\hline
\end{tabular}

Case 2 B: HTHP with pulsated heat input and convective cooling at steady-state operation

\begin{tabular}{|c|c|c|c|c|c|c|c|c|c|c|}
\hline Resistance (W/K) & $R e, w$ & $R e, w k$ & Re,inter & $R v$ & $R c, w$ & $R c, w k$ & Rc,inter & $R c, e x$ & Rhp & Rtot \\
\hline Numerical & 8.19E-03 & 4.47E-03 & $1.86 \mathrm{E}-04$ & $3.56 \mathrm{E}-04$ & $1.58 \mathrm{E}-03$ & $8.66 \mathrm{E}-04$ & 7.44E-05 & 0.838 & $1.57 \mathrm{E}-02$ & 0.854 \\
\hline \multicolumn{5}{|c|}{ Heat input (W) } & \multicolumn{6}{|c|}{770} \\
\hline
\end{tabular}


Table 4 LTHP thermal resistances for Case 3

Case 3 A: LTHP one heat source input

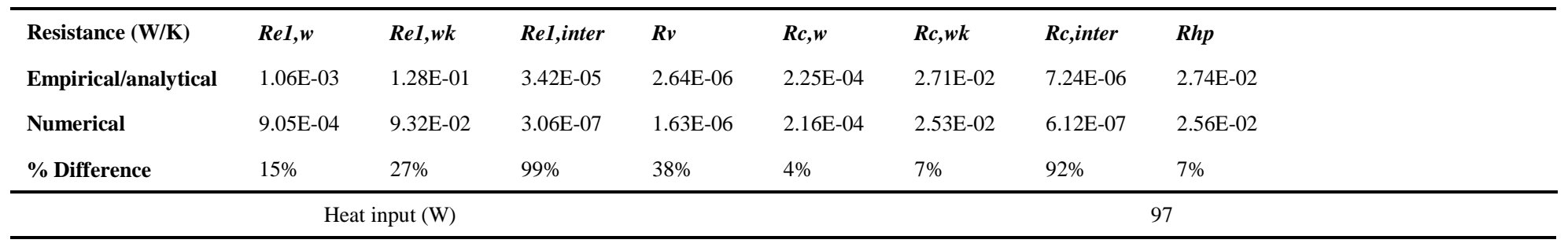

Case 3 B: LTHP two heat source inputs

\begin{tabular}{|c|c|c|c|c|c|c|c|c|c|c|}
\hline Resistance (W/K) & $\operatorname{Re1}, w$ & $\operatorname{Re1}, w k$ & Re1,inter & $\operatorname{Re} 2, w$ & $\operatorname{Re} 2, w k$ & Re2,inter & $R v$ & $R c, w$ & $R c, w k$ & Rc,inter \\
\hline Empirical/analytical & $9.45 \mathrm{E}-04$ & $1.28 \mathrm{E}-01$ & $3.91 \mathrm{E}-05$ & $9.45 \mathrm{E}-04$ & $1.28 \mathrm{E}-01$ & $3.91 \mathrm{E}-05$ & $2.85 \mathrm{E}-05$ & $9.45 \mathrm{E}-04$ & $1.28 \mathrm{E}-01$ & $3.60 \mathrm{E}-05$ \\
\hline Numerical & $9.11 \mathrm{E}-04$ & $9.40 \mathrm{E}-02$ & 3.31E-05 & $9.02 \mathrm{E}-04$ & $9.20 \mathrm{E}-02$ & $2.34 \mathrm{E}-04$ & $1.09 \mathrm{E}-04$ & $9.02 \mathrm{E}-04$ & $9.20 \mathrm{E}-02$ & $2.34 \mathrm{E}-04$ \\
\hline$\%$ Difference & $4 \%$ & $27 \%$ & $15 \%$ & $5 \%$ & $28 \%$ & $>300 \%$ & $283 \%$ & $5 \%$ & $28 \%$ & $>300 \%$ \\
\hline \multicolumn{5}{|c|}{ Heat input (W) } & \multicolumn{6}{|c|}{196} \\
\hline
\end{tabular}


Table 5 LTHP with channel flow cooling thermal resistances for Case 4

Case 4 A: LTHP channel flow cooling with a $10 \mathrm{~W}$ heat input and without fins

\begin{tabular}{|c|c|c|c|c|c|c|c|c|c|c|}
\hline Resistance (W/K) & $R e, w$ & $R e, w k$ & Re,inter & $R v$ & $R c, w$ & $R c, w k$ & Rc,inter & $R c, e x, w$ & $R h p$ & Rtot \\
\hline Empirical/analytical & $2.62 \mathrm{E}-02$ & $2.93 \mathrm{E}-02$ & $1.87 \mathrm{E}-05$ & $1.03 \mathrm{E}-04$ & $2.62 \mathrm{E}-02$ & 2.93E-02 & $1.87 \mathrm{E}-05$ & 5.99 & $1.09 \mathrm{E}-01$ & 6.1 \\
\hline Numerical & $2.61 \mathrm{E}-02$ & $2.91 \mathrm{E}-02$ & $1.93 \mathrm{E}-04$ & $1.06 \mathrm{E}-03$ & $2.60 \mathrm{E}-02$ & $2.90 \mathrm{E}-02$ & $1.25 \mathrm{E}-03$ & 5.34 & $1.12 \mathrm{E}-01$ & 5.45 \\
\hline \% Difference & $<1 \%$ & $<1 \%$ & $>300 \%$ & $>300 \%$ & $<1 \%$ & $1 \%$ & $>300 \%$ & $11 \%$ & $3 \%$ & $11 \%$ \\
\hline \multicolumn{11}{|c|}{ Heat input (W) } \\
\hline
\end{tabular}

Case 4 A: LTHP channel flow cooling with a 10 Wheat input and without fins

\begin{tabular}{|c|c|c|c|c|c|c|c|c|c|c|}
\hline Resistance (W/K) & $R e, w$ & $R e, w k$ & Re,inter & $R v$ & $R c, w$ & $R c, w k$ & Rc,inter & $R c, e x, w$ & Rhp & Rtot \\
\hline Empirical/analytical & $2.62 \mathrm{E}-02$ & $2.93 \mathrm{E}-02$ & $1.87 \mathrm{E}-05$ & $1.03 \mathrm{E}-04$ & $2.62 \mathrm{E}-02$ & 2.93E-02 & $1.87 \mathrm{E}-05$ & 5.99 & $1.09 \mathrm{E}-01$ & 6.1 \\
\hline Numerical & $2.61 \mathrm{E}-02$ & 2.91E-02 & $1.93 \mathrm{E}-04$ & $1.06 \mathrm{E}-03$ & $2.60 \mathrm{E}-02$ & $2.90 \mathrm{E}-02$ & $1.25 \mathrm{E}-03$ & 5.34 & $1.12 \mathrm{E}-01$ & 5.45 \\
\hline \% Difference & $<1 \%$ & $<1 \%$ & $>300 \%$ & $>300 \%$ & $<1 \%$ & $1 \%$ & $>300 \%$ & $11 \%$ & $3 \%$ & $11 \%$ \\
\hline \multicolumn{11}{|c|}{ Heat input (W) } \\
\hline
\end{tabular}

Case 4 B: LTHP channel flow cooling with a 20 Wheat input and without fins

\begin{tabular}{|c|c|c|c|c|c|c|c|c|c|c|}
\hline Resistance (W/K) & $R e, w$ & $R e, w k$ & Re,inter & $R v$ & $R c, w$ & $R c, w k$ & Rc,inter & $R c, e x, w$ & Rhp & Rtot \\
\hline Empirical/analytical & $2.62 \mathrm{E}-02$ & 2.93E-02 & $9.33 \mathrm{E}-06$ & $2.10 \mathrm{E}-05$ & $2.62 \mathrm{E}-02$ & $2.93 \mathrm{E}-02$ & $9.33 \mathrm{E}-06$ & 5.99 & $1.09 \mathrm{E}-01$ & 6.1 \\
\hline Numerical & $2.61 \mathrm{E}-02$ & 2.91E-02 & 7.43E-04 & $5.66 \mathrm{E}-04$ & $2.59 \mathrm{E}-02$ & $2.89 \mathrm{E}-02$ & $1.80 \mathrm{E}-04$ & 5.01 & $1.11 \mathrm{E}-01$ & 5.12 \\
\hline \% Difference & $<1 \%$ & $<1 \%$ & $>300 \%$ & $>300 \%$ & $<1 \%$ & $1 \%$ & $>300 \%$ & $16 \%$ & $2 \%$ & $16 \%$ \\
\hline \multicolumn{11}{|c|}{ Heat input (W) } \\
\hline
\end{tabular}

Case 4 C: LTHP channel flow cooling with a 10 Wheat input and fins

\begin{tabular}{|c|c|c|c|c|c|c|c|c|c|c|c|}
\hline Resistance (W/K) & $R e, w$ & $R e, w k$ & Re,inter & $R v$ & $R c, w$ & $R c, w k$ & $R c$, inter & $R c, e x, w$ & $R c, e x, f$ & $R h p$ & Rtot \\
\hline Empirical/analytical & $2.62 \mathrm{E}-02$ & $2.93 \mathrm{E}-02$ & 3.83E-05 & $4.80 \mathrm{E}-07$ & $2.62 \mathrm{E}-02$ & $2.93 \mathrm{E}-02$ & $3.83 \mathrm{E}-05$ & 6.47 & 1.86 & $1.09 \mathrm{E}-01$ & 1.55 \\
\hline Numerical & $2.61 \mathrm{E}-02$ & $2.90 \mathrm{E}-02$ & $1.46 \mathrm{E}-04$ & $5.99 \mathrm{E}-04$ & $5.01 \mathrm{E}-03$ & $2.88 \mathrm{E}-02$ & $7.48 \mathrm{E}-04$ & 5.96 & 2.77 & $9.01 \mathrm{E}-02$ & 1.98 \\
\hline \% Difference & $<1 \%$ & $<1 \%$ & $281 \%$ & $>300 \%$ & $81 \%$ & $2 \%$ & $>300 \%$ & $8 \%$ & $49 \%$ & $18 \%$ & $28 \%$ \\
\hline Heat input (W) & 10 & Heat $\mathrm{c}$ & itput from & all $(\mathrm{W})$ & 4 & Heat $\mathrm{c}$ & atput from $\mathrm{f}$ & $\mathrm{ls}(\mathrm{W})$ & & 5 & \\
\hline
\end{tabular}

Case 4 D: LTHP channel flow cooling with a 20 Wheat input and fins

\begin{tabular}{|c|c|c|c|c|c|c|c|c|c|c|c|}
\hline Resistance (W/K) & $R e, w$ & $R e, w k$ & Re,inter & $R v$ & $R c, w$ & $R c, w k$ & Rc,inter & $R c, e x, w$ & $R c, e x, f$ & $R h p$ & Rtot \\
\hline Empirical/analytical & $2.62 \mathrm{E}-02$ & $2.93 \mathrm{E}-02$ & $1.93 \mathrm{E}-05$ & $1.20 \mathrm{E}-07$ & $2.62 \mathrm{E}-02$ & $2.93 \mathrm{E}-02$ & $1.93 \mathrm{E}-05$ & 6.47 & 1.86 & $1.09 \mathrm{E}-01$ & 1.55 \\
\hline Numerical & $2.61 \mathrm{E}-02$ & $2.91 \mathrm{E}-02$ & $1.35 \mathrm{E}-05$ & $5.20 \mathrm{E}-05$ & $2.61 \mathrm{E}-02$ & $2.92 \mathrm{E}-02$ & $6.70 \mathrm{E}-05$ & 6.84 & 2.88 & $1.10 \mathrm{E}-01$ & 2.14 \\
\hline$\%$ Difference & $<1 \%$ & $<1 \%$ & $30 \%$ & $>300 \%$ & $<1 \%$ & $<1 \%$ & $246 \%$ & $6 \%$ & $55 \%$ & $<1 \%$ & $38 \%$ \\
\hline Heat input (W) & 20 & Heat $\mathrm{C}$ & atput from & all (W) & 7 & Heat & utput from & ns (W) & & 13 & \\
\hline
\end{tabular}


Table 6 HTHP thermal resistances for Case 5 A-

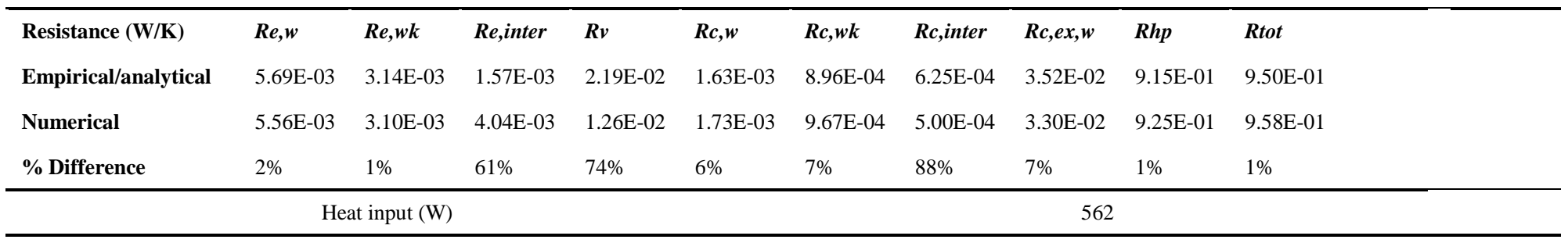

Case 5 B: Constant heat input with convective cooling and no fins

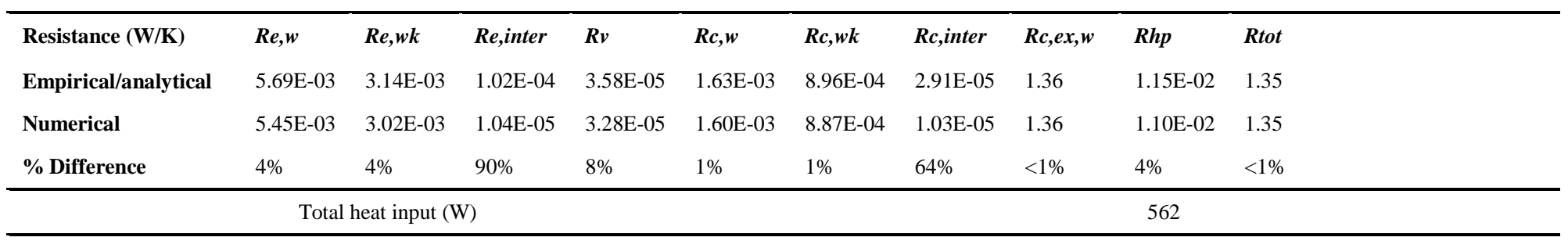

Case 5 C: Constant heat input with convective cooling and 6 condenser fins

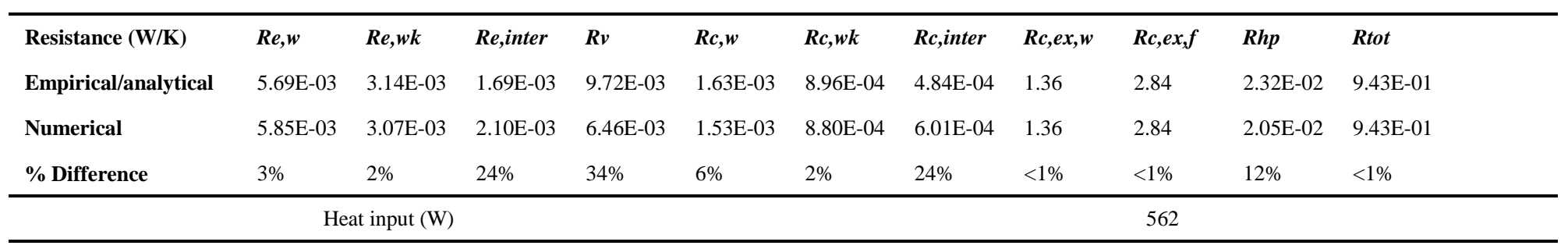

Case 5 D: Convective heat input with convective cooling and no fins

\begin{tabular}{|c|c|c|c|c|c|c|c|c|c|c|c|}
\hline Resistance (W/K) & $R e, e x$ & $R e, w$ & $R e, w k$ & Re,inter & $R v$ & $R c, w$ & $R c, w k$ & Rc,inter & $R c, e x, w$ & $R h p$ & Rtot \\
\hline Empirical/analytical & $1.87 \mathrm{E}-01$ & $5.69 \mathrm{E}-03$ & $3.14 \mathrm{E}-03$ & 4.33E-04 & 8.37E-04 & $1.63 \mathrm{E}-03$ & $8.96 \mathrm{E}-04$ & $1.24 \mathrm{E}-04$ & 1.34 & $1.27 \mathrm{E}-02$ & 1.54 \\
\hline Numerical & $1.88 \mathrm{E}-01$ & $5.47 \mathrm{E}-03$ & $3.02 \mathrm{E}-03$ & $1.69 \mathrm{E}-04$ & $6.23 \mathrm{E}-04$ & $1.61 \mathrm{E}-03$ & 8.61E-04 & $2.29 \mathrm{E}-04$ & 1.34 & $1.20 \mathrm{E}-02$ & 1.54 \\
\hline$\%$ Difference & $<1 \%$ & $4 \%$ & $4 \%$ & $61 \%$ & $26 \%$ & $<1 \%$ & $4 \%$ & $85 \%$ & $<1 \%$ & $6 \%$ & $<1 \%$ \\
\hline Heat input (W) & & & & & & & & & 447 & & \\
\hline
\end{tabular}

Case 5 E: Convective heat input with convective cooling and 6 fins

\begin{tabular}{|c|c|c|c|c|c|c|c|c|c|c|c|c|}
\hline Resistance (W/K) & Re,ex & $R e, w$ & $R e, w k$ & Re,inter & $R v$ & $R c, w$ & $R c, w k$ & Rc,inter & $R c, e x, w$ & $R c, e x, f$ & $R h p$ & Rtot \\
\hline Empirical/analytical & $1.87 \mathrm{E}-01$ & $5.69 \mathrm{E}-03$ & $3.14 \mathrm{E}-03$ & $6.05 \mathrm{E}-04$ & $1.87 \mathrm{E}-03$ & $1.63 \mathrm{E}-03$ & $8.96 \mathrm{E}-04$ & $1.73 \mathrm{E}-04$ & 1.36 & 2.84 & $1.40 \mathrm{E}-02$ & $9.34 \mathrm{E}-01$ \\
\hline Numerical & $1.85 \mathrm{E}-01$ & $5.62 \mathrm{E}-03$ & 3.07E-03 & $2.60 \mathrm{E}-04$ & $1.51 \mathrm{E}-03$ & $1.62 \mathrm{E}-03$ & $9.09 \mathrm{E}-04$ & $9.74 \mathrm{E}-05$ & 1.36 & 2.84 & $1.31 \mathrm{E}-02$ & $9.33 \mathrm{E}-01$ \\
\hline$\%$ Difference & $1 \%$ & $1 \%$ & $2 \%$ & $57 \%$ & $19 \%$ & $<1 \%$ & $1 \%$ & $44 \%$ & $<1 \%$ & $<1 \%$ & $7 \%$ & $<1 \%$ \\
\hline Heat input & & 616 & Total & outnut & bugh wall & & 194 & \multicolumn{4}{|c|}{ Total heat output through fins (W) } & 424 \\
\hline
\end{tabular}


Table 7 HTHP with channel flow cooling thermal resistances for Case 5 F-I

Case 5 F: Constant heat input without fins

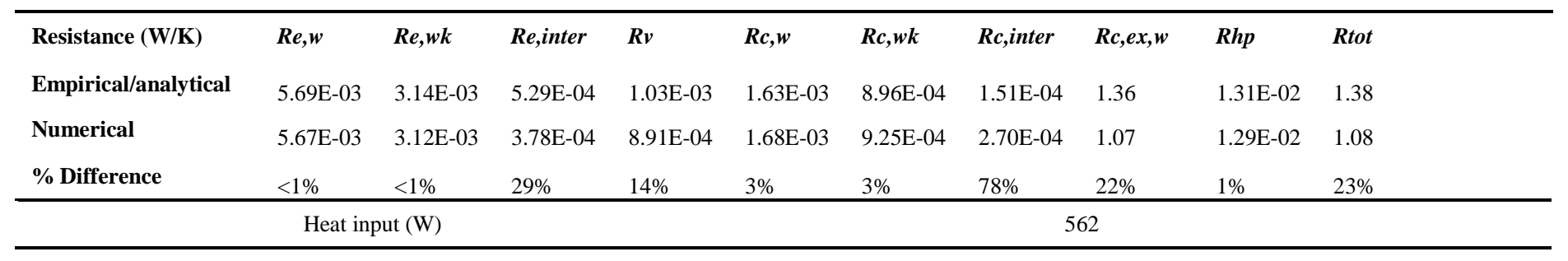

Case 5 G: Constant heat input with fins

\begin{tabular}{|c|c|c|c|c|c|c|c|c|c|c|c|}
\hline Resistance (W/K) & $R e, w$ & $R e, w k$ & Re,inter & $R v$ & $R c, w$ & $R c, w k$ & Rc,inter & $R c, e x, w$ & $R c, e x, f$ & $R h p$ & Rtot \\
\hline Empirical/analytical & $5.69 \mathrm{E}-03$ & $3.14 \mathrm{E}-03$ & $4.55 \mathrm{E}-03$ & $1.40 \mathrm{E}-01$ & $1.63 \mathrm{E}-03$ & $8.96 \mathrm{E}-04$ & $1.30 \mathrm{E}-03$ & $1.36 \mathrm{E}+00$ & 2.84 & $1.56 \mathrm{E}-01$ & 1.51 \\
\hline Numerical & $5.67 \mathrm{E}-03$ & $3.12 \mathrm{E}-03$ & $2.46 \mathrm{E}-02$ & $1.35 \mathrm{E}-01$ & $1.32 \mathrm{E}-03$ & $8.78 \mathrm{E}-04$ & $1.49 \mathrm{E}-01$ & $9.75 \mathrm{E}-01$ & 2.52 & $3.15 \mathrm{E}-01$ & 1.25 \\
\hline$\%$ Difference & $<1 \%$ & $<1 \%$ & $81 \%$ & $3 \%$ & $19 \%$ & $2 \%$ & $300 \%<$ & $28 \%$ & $11 \%$ & $102 \%$ & $17 \%$ \\
\hline \multicolumn{2}{|c|}{ Heat input (W) } & 562 & Total c & Itput form $v$ & $\operatorname{alls}(\mathrm{W})$ & 388 & & Total output & om fins ( & & 177 \\
\hline
\end{tabular}

Case 5 H: Convective heat input without fins

\begin{tabular}{|c|c|c|c|c|c|c|c|c|c|c|}
\hline Resistance (W/K) & $R e, w$ & $R e, w k$ & Re,inter & $R v$ & $R c, w$ & $R c, w k$ & Rc,inter & $R c, e x, w$ & Rhp & Rtot \\
\hline Empirical/analytical & $5.69 \mathrm{E}-03$ & $3.14 \mathrm{E}-03$ & $6.03 \mathrm{E}-04$ & $1.65 \mathrm{E}-03$ & $1.63 \mathrm{E}-03$ & 8.96E-04 & $1.72 \mathrm{E}-04$ & 1.36 & $1.38 \mathrm{E}-02$ & 1.38 \\
\hline Numerical & $6.14 \mathrm{E}-03$ & $3.38 \mathrm{E}-03$ & $4.78 \mathrm{E}-04$ & $1.46 \mathrm{E}-03$ & $1.77 \mathrm{E}-03$ & $9.76 \mathrm{E}-04$ & $3.42 \mathrm{E}-04$ & 1.03 & $1.45 \mathrm{E}-02$ & 1.04 \\
\hline$\%$ Difference & $8 \%$ & $8 \%$ & $21 \%$ & $11 \%$ & $9 \%$ & $9 \%$ & $99 \%$ & $24 \%$ & $6 \%$ & $24 \%$ \\
\hline \multicolumn{11}{|c|}{ Heat input (W) } \\
\hline
\end{tabular}

Case 5 I: Convective heat input with fins

\begin{tabular}{|c|c|c|c|c|c|c|c|c|c|c|c|}
\hline Resistance (W/K) & $R e, w$ & $R e, w k$ & Re,inter & $R v$ & $R c, w$ & $R c, w k$ & Rc,inter & $R c, e x, w$ & $R c, e x, f$ & $R h p$ & Rtot \\
\hline Empirical/analytical & $5.69 \mathrm{E}-03$ & $3.14 \mathrm{E}-03$ & 7.49E-04 & $2.62 \mathrm{E}-03$ & $1.63 \mathrm{E}-03$ & $8.96 \mathrm{E}-04$ & $2.14 \mathrm{E}-04$ & 1.36 & 2.84 & $1.49 \mathrm{E}-02$ & 1.38 \\
\hline Numerical & $5.67 \mathrm{E}-03$ & $3.12 \mathrm{E}-03$ & 8.55E-04 & $2.65 \mathrm{E}-03$ & $1.39 \mathrm{E}-03$ & $9.15 \mathrm{E}-04$ & $8.40 \mathrm{E}-04$ & $9.74 \mathrm{E}-01$ & 2.48 & $1.54 \mathrm{E}-02$ & $9.89 \mathrm{E}-01$ \\
\hline$\%$ Difference & $<1 \%$ & $<1 \%$ & $12 \%$ & $1 \%$ & $14 \%$ & $2 \%$ & $75 \%$ & $29 \%$ & $13 \%$ & $3 \%$ & $28 \%$ \\
\hline Heat input (V & & 734 & \multicolumn{3}{|c|}{ Total output from wall (W) } & 567 & \multicolumn{4}{|c|}{ Total output from fins (W) } & 215 \\
\hline
\end{tabular}

